\title{
Electrical Stimulation to Enhance Axon Regeneration After Peripheral Nerve Injuries in Animal Models and Humans
}

\author{
Tessa Gordon ${ }^{1}$
}

Published online: 11 January 2016

(C) The American Society for Experimental NeuroTherapeutics, Inc. 2016

\begin{abstract}
Injured peripheral nerves regenerate their lost axons but functional recovery in humans is frequently disappointing. This is so particularly when injuries require regeneration over long distances and/or over long time periods. Fat replacement of chronically denervated muscles, a commonly accepted explanation, does not account for poor functional recovery. Rather, the basis for the poor nerve regeneration is the transient expression of growth-associated genes that accounts for declining regenerative capacity of neurons and the regenerative support of Schwann cells over time. Brief low-frequency electrical stimulation accelerates motor and sensory axon outgrowth across injury sites that, even after delayed surgical repair of injured nerves in animal models and patients, enhances nerve regeneration and target reinnervation. The stimulation elevates neuronal cyclic adenosine monophosphate and, in turn, the expression of neurotrophic factors and other growth-associated genes, including cytoskeletal proteins. Electrical stimulation of denervated muscles immediately after nerve transection and surgical repair also accelerates muscle reinnervation but, at this time, how the daily requirement of long-duration electrical pulses can be delivered to muscles remains a practical issue prior to translation to patients. Finally, the technique of inserting autologous nerve grafts that bridge between a donor nerve and an adjacent recipient denervated nerve stump significantly improves nerve regeneration after delayed nerve repair, the donor nerves sustaining
\end{abstract}

Tessa Gordon

tessat.gordon@gmail.com

1 Department of Surgery, The Hospital for Sick Children, Toronto, Ontario M5G 1X8, Canada the capacity of the denervated Schwann cells to support nerve regeneration. These reviewed methods to promote nerve regeneration and, in turn, to enhance functional recovery after nerve injury and surgical repair are sufficiently promising for early translation to the clinic.

Keywords Peripheral nerve regeneration - Peripheral nerve injury $\cdot$ Electrical stimulation $\cdot$ Delayed nerve repair .

Side-to-side crossbridges

\section{Introduction}

Injured nerves in the peripheral nervous system (PNS) regenerate their lost axons in contrast to those nerves in the central nervous system (CNS) that cannot. The Schwann cells within the denervated distal nerve stump provide the essential support for the regeneration of the PNS nerve fibers in contrast to the analogous glial cells of the CNS, the oligodendrocytes [1]. Yet, the recovery of function after human peripheral nerve injuries is frequently disappointing. This is the case particularly for injuries that are sustained at some distance from the denervated targets, requiring that the injured nerves regenerate over long distances and over long periods of time at the established rate of $\sim 1 \mathrm{~mm} /$ day [2].

The basis for this poor regeneration is explored in this review before presenting the evidence that brief electrical stimulation is effective in accelerating axon outgrowth across injury sites $[3,4]$ that, even after delayed surgical repair of injured peripheral nerves, functional recovery is enhanced [5]. Associated with this enhancement, the electrical stimulation upregulates the expression of neurotrophic factors and, in turn, growth-associated genes [6,7]. Although exogenous application of growth factors is effective in promoting nerve regeneration after delayed nerve repair or through nerve grafts that connect transected nerve stumps [8-11], and even though 
developments have been made in the delivery of these factors [11], the question remains as to whether the stimulation of endogenous sources of these factors and other as yet unknown mediators of nerve regeneration is more appropriate. Additionally, recent work has indicated an accelerating effect on target reinnervation when denervated muscle is electrically stimulated immediately after nerve transection but, how the daily requirement of long-duration electrical pulses can be delivered to muscles remains a practical question that needs to be addressed prior to clinical application [12].

Finally, a relatively new technique has been introduced that has the potential to prevent the progressive deterioration of the Schwann cell support of regenerating nerves. The technique of inserting nerve autografts through perineurial windows in peripheral nerves to bridge between a donor nerve and a recipient denervated distal nerve stump, encourages the regeneration of axons from the donor nerve into the recipient denervated nerve stump and allows limited axon regeneration proximal and distal to the nerve autografts that bridge the two nerves, the side-toside cross-bridges. In turn, these cross-bridges allow for greatly improved nerve regeneration through the chronically denervated distal nerve stump when the proximal nerve stump is surgically united with the distal "protected" nerve stump [13-15]. Even when the surgical coaptation of the transected nerve stumps is performed immediately after injury, the long distance of nerve regeneration would otherwise allow for the deterioration of the growth support of the chronically denervated distal nerve stumps. The occupation of some of the denervated endoneurial tubes by the regenerated axons from the donor nerve sustains the growth permissive environment. The distal growth of the axons toward the denervated targets may also prevent the rapid denervation atrophy that normally occurs.

\section{The Window of Opportunity for Nerve Regeneration is Restricted}

Normally the regeneration of injured nerves is excellent in small rodents, at least with respect to numbers of axons that regenerate and reinnervate distal targets after crush and transection injuries $[16,17]$. The axons that are separated from their neuronal cell bodies lose their myelin sheaths and undergo Wallerian degeneration [18-24]. The denervated Schwann cells, in turn, line the endoneurial tubes and cross the surgical gap as the Bands of Bungner that guide regenerating axons across the crush or transection site, through the tubes, and back to the denervated targets $[24,25]$. It is often said that, even without surgical repair, axons are emitted from the proximal nerve stump and frequently "find" their way back to the denervated nerve stump [26]. A dramatic illustration of this phenomenon of nerve outgrowth from the proximal nerve stump is the growth of axons along the surface of denervated muscle, the axons frequently re-entering denervated intramuscular nerve stumps (Fig. 1). This growth is associated with the outpouring of Schwann cells from the implanted proximal nerve stump that "support" the regenerating axons from the stump. However, this growth is limited by the distance between the implanted nerve and the denervated intramuscular nerve stump. Additional factors include the number of Schwann cells that can migrate from the proximal nerve stump and the transected intramuscular nerves, and the distance over which the Schwann cells can migrate to reach the intramuscular nerves and/or the denervated endplates (Gordon, unpublished data). Evidence to date indicates that Schwann cells lead and the regenerating axons follow from the proximal nerve stump [27].

The question remains as to why functional outcomes are so poor after delayed nerve surgeries or injuries suffered where long periods of time pass before target reinnervation would be expected. The answer to the question is generally assumed to be that regenerating axons fail to reinnervate target muscles due to irreversible denervation atrophy with ultimate fat replacement $[2,25$, 28]. Experimentally, we asked the question of the consequences of the long periods of isolation of the injured neurons that regenerate their lost axons from their denervated targets (chronic axotomy of the neurons), the long periods of denervation of the Schwann cells in the distal nerve stumps (chronic Schwann cell denervation), and, finally, the chronic denervation of the muscles (chronic muscle denervation). Each of these conditions feature in human patients after delayed nerve repair. They also feature after immediate nerve repair for peripheral nerves that are injured close to the spinal cord and the dorsal root ganglia.

We addressed the question of the basis for poor functional outcomes in a rat model of delayed nerve repair. We used a cross-suture surgical paradigm with and without an autograft in which we progressively prolonged the period of time of chronic axotomy of the neurons, of chronic denervation of the Schwann cells, and of the chronic denervation of the muscles independently of each other (Fig. 2) [5, 8-10, 17, 29-36]. In the first series of experiments, we chronically axotomized the neurons or chronically denervated the distal nerve stump [17, 29]. We prolonged chronic axotomy for up to 12 months before suturing the proximal nerve stump of the chronically axotomized neurons to the distal stump of a freshly transected nerve; after at least 6 months muscle reinnervation was determined. We found that the numbers of nerves that reinnervated the denervated muscle declined exponentially to reach plateau levels of $\sim 35 \%$ of the numbers that reinnervated the denervated muscle after immediate nerve repair [17]. Chronic denervation of the distal nerve stump was even more detrimental to nerve regeneration with progressively fewer freshly transected nerves regenerating and reinnervating the denervated muscles as the chronic denervation was prolonged, the numbers declining to $\sim 10 \%$ [29]. Contrary to the belief that regenerating nerves could not reinnervate chronically denervated muscle because the muscle fibers had degenerated and were replaced by fat, retrograde labeling of those axons that were able to regenerate into the denervated 


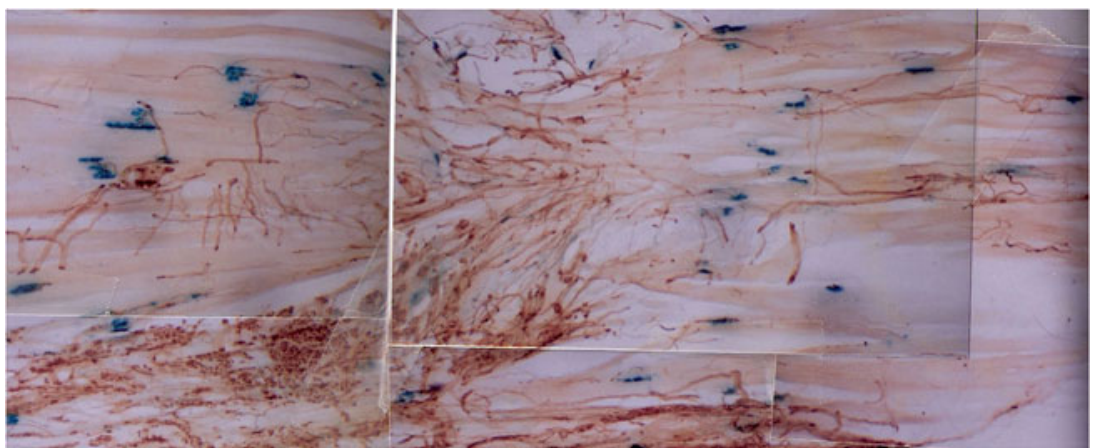

Fig. 1 Outgrowth of regenerating axons from a common peroneal nerve sutured directly to denervated soleus muscle. Silver nitrate-stained axons grow out from the suture site (at the bottom of the micrograph) and follow

nerve stump revealed that the chronic denervation reduced the capacity of the freshly axotomized neurons to regenerate their axons through the chronically denervated nerve stump [30].

a

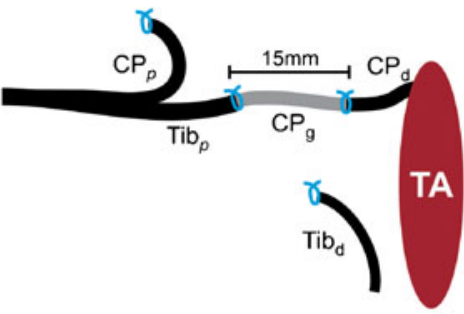

C
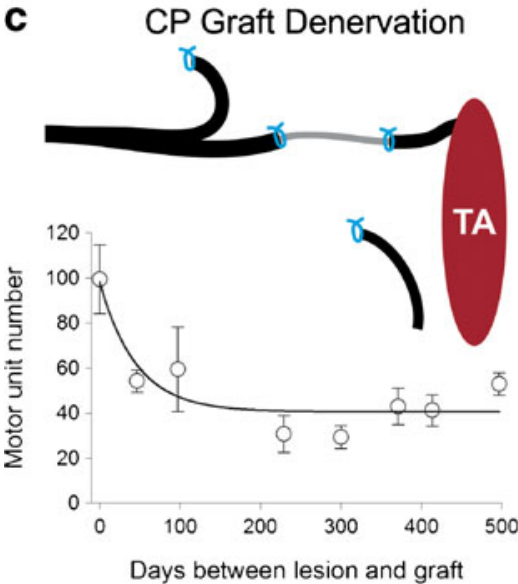

Fig. 2 Progressive failure of regenerating axons to grow through an autograft into the distal nerve stump and to reinnervate denervated muscles after delayed nerve repair. (a) The experimental protocol was to tease Sprague-Dawley rat ventral roots to evoke and record isometric contractile force from muscle fibers in the reinnervated tibialis anterior (TA) muscle that were reinnervated by single tibial (Tib) axons (motor units) at least 6 months after cross-suturing the proximal tibial (Tib $\left.b_{p}\right)$ nerve stump to the distal common peroneal $\left(\mathrm{CP}_{\mathrm{d}}\right)$ nerve via a $\mathrm{CP}$ nerve the muscle fibers to reinnervate many denervated endplates that are identified by their immunostaining with cholinesterase (blue)

Hence, chronic denervation of the muscle was not responsible for the low percentage of axons that did regenerate through the atrophic Schwann cells. Interestingly, the remaining atrophic

b
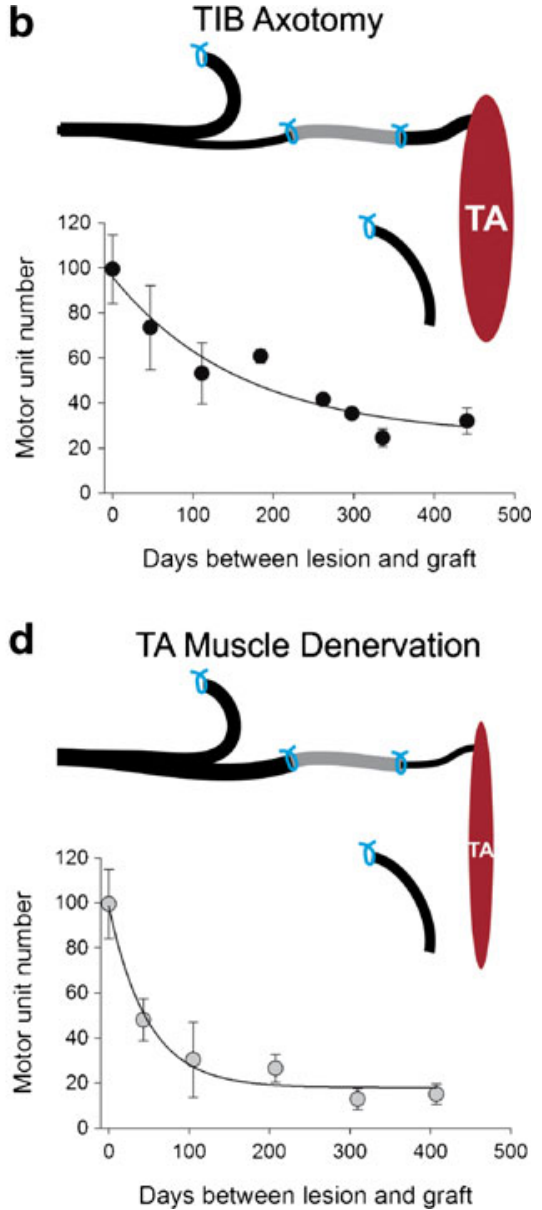

autograft $\left(\mathrm{CP}_{\mathrm{g}}\right)$ taken from the contralateral hindlimb. The cross-suture took place either (a) immediately or after a delay of up to 500 days, resulting in (b) chronic TIB axotomy, (c) chronic CP graft denervation, or (d) chronic TA muscle denervation. The relative contributions of (b) chronic axotomy, (c) chronic CP nerve denervation, and (d) TA muscle denervation to the decline in the number of regenerating Tib nerves that reinnervated the denervated TA muscle (motor unit number) are seen with each contributing to the progressive failure of nerve regeneration 
Schwann cells were able to myelinate the regenerated axons normally and the regenerated nerves reinnervated as many as 3 times the number of muscle fibers than they normally do to enlarge the muscle units (number of muscle fibers per motoneuron) as much as they do under conditions of partial denervation of freshly denervated muscles [29, 37]. Further analysis of the capacity of chronically denervated Schwann cells to support axonal regeneration was done by encouraging nerve regeneration through a chronically denervated autograft into a freshly denervated muscle, demonstrating the key role that freshly denervated Schwann cells play in supporting the regeneration of axons (Fig. 2) [36]. In these experiments, the tibial nerve was cross-sutured to the distal nerve stump of the common peroneal nerve via a $12-\mathrm{mm}$ common peroneal nerve autograft from the contralateral leg. Either the tibial motoneurons were chronically axotomized, the Schwann cells in the nerve autograft chronically denervated, or the tibialis anterior muscle chronically denervated for periods of up to 500 days to isolate the effects of chronic Schwann cell denervation from chronic muscle denervation (Fig. 2a-d). These experiments confirmed the detrimental effect of chronic axotomy on nerve regeneration as well as differentiating between the rapid detrimental effect of Schwann cell denervation within the autograft and the slower but greater effect of the denervation of the intramuscular nerves and the muscle.

While the basis for the restricted window of opportunity for nerve regeneration over time and/or distance is not yet fully understood, the transient expression of growth-associated genes concomitant with the declining regenerative capacity of the neurons in rat models of delayed nerve repair is likely to be sufficient to account for the progressive failure of effective nerve regeneration. Analysis of the expression of growth-associated genes in motoneurons and within denervated distal nerve stumps revealed that the expression is transient (Fig. 3). There is a rapid upregulation of neurotrophic factors and their receptors in motoneurons and in Schwann cells, but this upregulation is short-lived, declining to baseline levels within a month or more of chronic axotomy and chronic denervation, respectively [31, 39-42]. Examples include the upregulation of neurotrophic factors, galectin-1, and cytoskeletal proteins, including actin and T- $\alpha-1$ tubulin in the neurons [43-46], and neurotrophic factors and their receptors in the Schwann cells (Fig. 3a) [31, 41, 42, 47-49]. A specific example of upregulation of T- $\alpha-1$ tubulin in the neurons is shown in Fig. 3b, and of glial cell line-derived neurotrophic factor (GDNF) and the p75 receptor for the neurotrophins in Schwann cells (Fig. 3c, d).
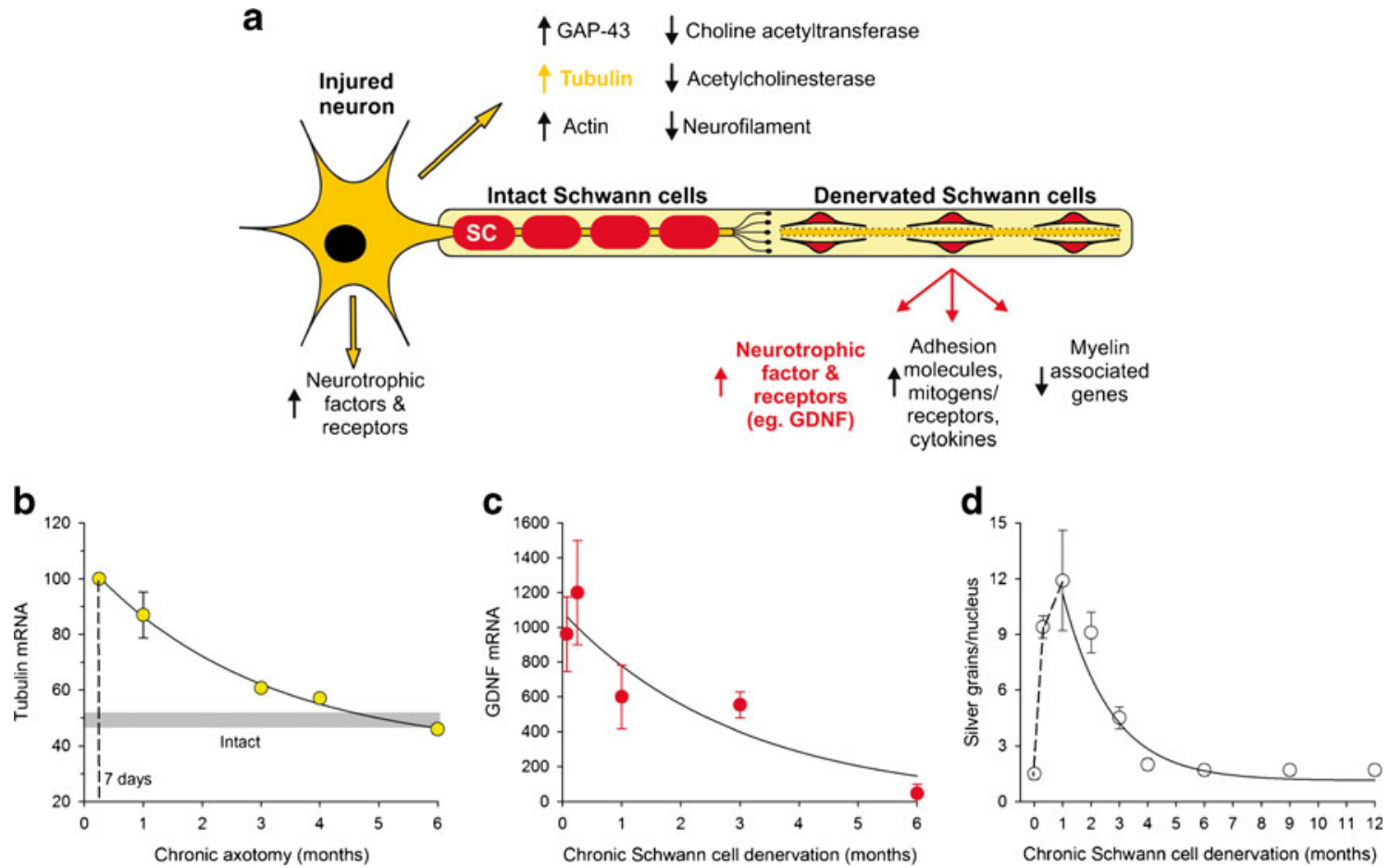

Fig. 3 The transient expression of regeneration-associated genes in injured neurons after transecting the peripheral nerve. (a) The chromatolytic reaction of an injured motoneuron includes the movement of the nucleus to an eccentric position with expression of several growth-associated genes (GAGs) that include the neurotrophic factors and their receptors. There is a switch from the transmitting to the growth state in the axotomized motoneurons that includes the downregulation of transmitter associated genes (choline acetyltransferase and acetylcholinesterase) and the cytoskeletal protein, neurofilament, concurrent with a decline in the

size of the axons proximal to the lesion [38]. The cytoskeletal proteins of tubulin and actin are upregulated, as are several growth-associated proteins (GAPs) that include GAP-43. However, this expression is transient as shown by the examples of the decline in the expression of (b) tubulin in chronically axotomized sciatic motoneurons, (c) glial-derived neurotrophic factor (GDNF), and the p75 receptor for the neurotrophic factors in chronically denervated Schwann cells. Mean \pm SE bars are plotted in the graphs and the data points are fitted by exponential lines 


\section{Brief Electrical Stimulation Accelerates Axon Outgrowth Across the Nerve Injury Site After Both Immediate and Delayed Nerve Repair}

The concept of a latent period that precedes the outgrowth of regenerating axons from a proximal nerve stump into a denervated distal nerve stump was the result of experiments that were designed to examine the rate of nerve regeneration. The latent period of nerve regeneration was determined by extrapolation of the regression line of the distance of nerve regeneration against the days after the nerve injury [50]. Periods of as short as a day or as long as 3 days were described with axons regenerating thereafter at rates of $1-3 \mathrm{~mm} /$ day in humans and rats, respectively [50-55]. When motoneurons that regenerated their axons through a site of femoral nerve transection and microsurgical coaptation were back-labeled with fluorescent dyes $25 \mathrm{~mm}$ from the repair site, the numbers of these neurons increased to their maximum over a period of 8-10 weeks (Fig. 4a) [4]. This period of time was considerably longer than the predicted 2 weeks of regeneration calculated with a consideration of a latent period of 2-3 days and the reported regeneration rate of $3 \mathrm{~mm} /$ day in the rat. We termed this regeneration "staggered" with the prediction that the "staggering" occurs at the injury site where Cajal had described axons wondering at the suture site with some axons even turning to grow back towards the proximal nerve stump [26]. Indeed, this was the case, because back-labeling of the neurons whose regenerated axons had just crossed into the distal nerve stump revealed that a period of 3-4 weeks transpired before all the axons crossed the site of coapted femoral
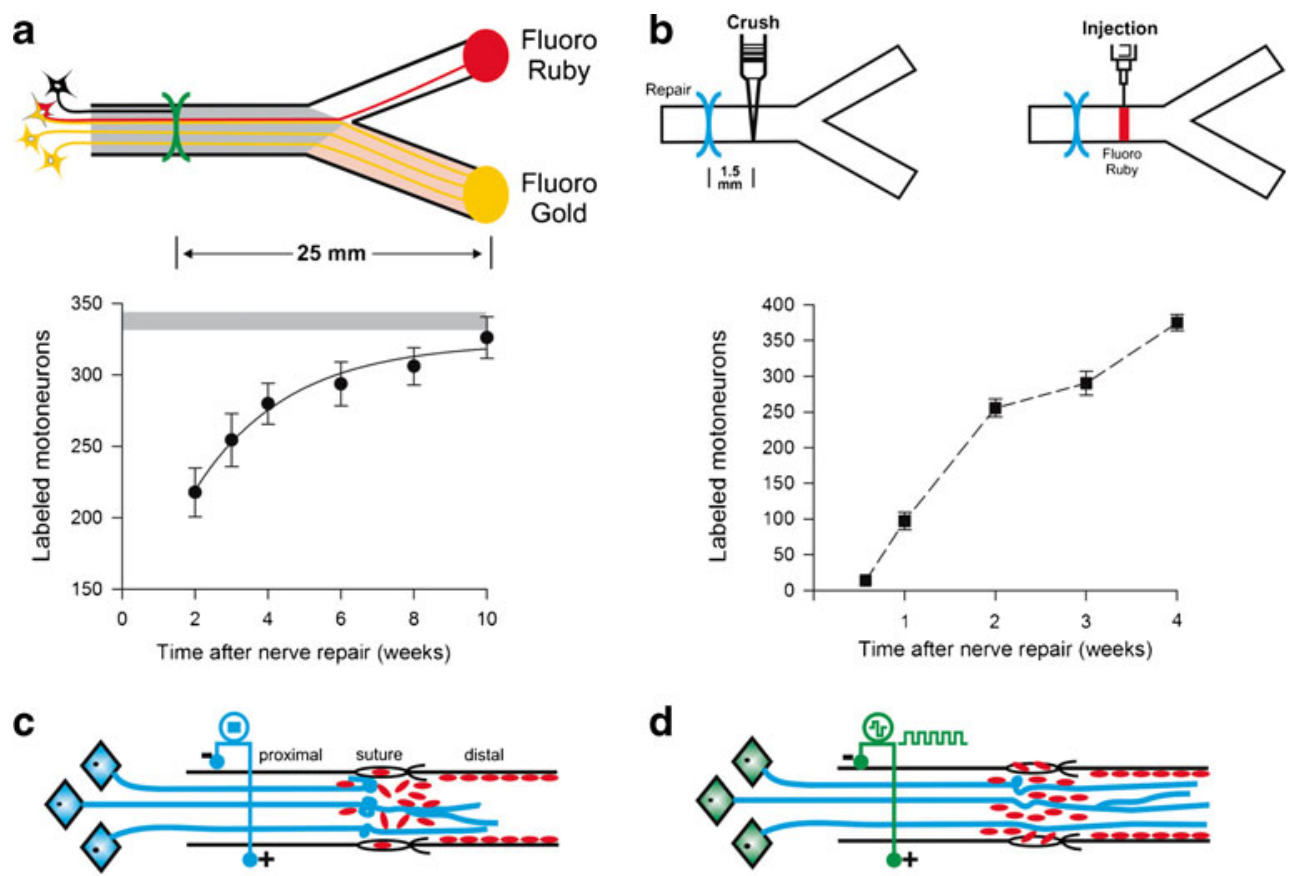

d
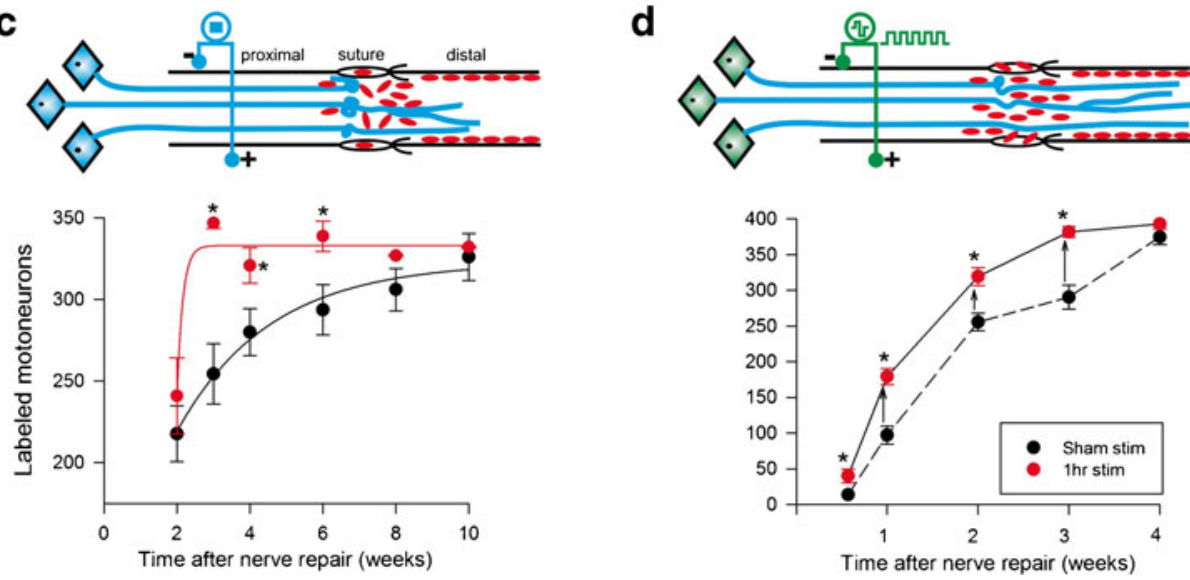

Fig. 4 Brief 20-Hz electrical stimulation accelerates axon outgrowth across the surgical site of nerve repair. (a) The rat femoral nerve was transected and microsurgically repaired $20 \mathrm{~mm}$ from the branching of the nerves into the motor branch to the quadriceps muscle and the cutaneous saphenous nerve branch. The number of backlabeled motoneurons that regenerated their axons into both the branches and were backlabeled $25 \mathrm{~mm}$ from the suture site with fluororuby and fluorogold, increased progressively over an 8-10-week period of time. (b) Staggered axon regeneration was due to the "staggering" of regenerating axons across

the suture site over a 4-week period as determined by counting motoneurons that were backlabeled by crushing the femoral nerve stump $1.5 \mathrm{~mm}$ from the repair site. $(\mathbf{c}, \mathbf{d})$ The "staggered axon regeneration" across the suture site was accelerated significantly $(* p<0.05)$ by a 1 -h period of $20-\mathrm{Hz}$ continuous electrical stimulation such that all motoneurons regenerated their axons over a distance of $25 \mathrm{~mm}$ within 3 weeks rather than 8-10 weeks with sham stimulation and motoneurons regenerated their axons significantly more qucikly across the suture site into the distal nerve stump 
nerve stumps (Fig. 4b) [3], and because Witzel et al. [56], using transgenic mice that expressed fluorescent protein in their axons, demonstrated the "staggering" of regenerating axons as they crossed a suture line.

Electrical stimulation of the transected nerve proximal to the site of transection and surgical repair reduces the staggering of the axons as they regenerate across the suture site: a 2 -week period of continuous stimulation at $20 \mathrm{~Hz}$ or even $1 \mathrm{~h}$ of stimulation promoted the outgrowth of regenerating axons across the suture line with the result that all motoneurons regenerated their axons over the 25-mm distance within 3 weeks (Fig. 4c, d). The electrical stimulation did not affect the rate of axonal transport as determined by injecting radiolabeled thymidine into the neurons [3]. The rationale for stimulating the nerve for 2 weeks was that this period of electrical stimulation after a crush injury of the nerve to the soleus muscle of the rabbit accelerated recovery of contractile forces in the muscle [57]. The finding that electrical stimulation accelerated the recovery of muscle contractile force indicated a positive effect of electrical stimulation without localizing the site of action of the electrical stimulation. Moreover, later findings by Pockett and Gavin [58] demonstrated the return of reflex contractions of ankle extensor muscles after electrical stimulation of the crushed sciatic nerve. Again, though, the site of action of the electrical stimulation was unknown. These investigators reduced the time period of electrical stimulation to record positive effects for durations as short as $15 \mathrm{~min}$. In our study, we found that a 1-h period of electrical stimulation was effective in accelerating axon regeneration, this finding being serendipitous because longer periods of electrical stimulation were ineffective for sensory neurons whose axon outgrowth was also accelerated by 1-h of electrical stimulation but not by electrical stimulation for longer periods of time [59]. Most importantly, we established that the action potentials, generated by the brief electrical stimulation of the axons proximal to the lesion site and transmitted back to the soma of the neurons, were essential for the efficacy of the accelerated axon outgrowth in response to the electrical stimulation. This was because a tetrodotoxin blockade of these potentials obliterated the effect of the electrical stimulation [4].

The findings of accelerated nerve outgrowth after immediate nerve repair have been replicated many times for several different nerves, including the sciatic nerve and its main tributary nerve branches [60-91]. Presently, neither the frequency nor the duration of electrical stimulation have been considered in detail, although the crushed facial nerve was stimulated daily until functional recovery at $20 \mathrm{~Hz}$ for $30 \mathrm{~min} /$ day, the stimulation commencing a day after the crush injury $[67,81,82]$; the transected sciatic nerve was stimulated for only $20 \mathrm{~min}$ after delayed nerve repair [92], and for 10 min after a transection injury that was repaired via a silicone tube filled with a collagen gel [93].
Only 2 studies $[5,92]$ have addressed the important clinical and unanswered question of whether electrical stimulation is effective under conditions of the chronic axotomy and chronic denervation, conditions that human nerves suffer even after immediate nerve repair as a consequence of long distances between the site of nerve repair and denervated targets. The study of Huang et al. [92] indicated a very small but significant increase of $\sim 10 \%$ and $3 \%$ in the regeneration of axons by motor and sensory neurons, respectively, when the sciatic nerve was subjected to a 20-min period of low-frequency electrical stimulation after a delayed nerve repair via a 5-mm long hollow nerve conduit. Hence, the question of efficacy of the electrical stimulation on chronically injured nerves remained prior to our more recent study in which we again used a crosssuture technique to examine whether the brief $1-\mathrm{h} 20-\mathrm{Hz}$ electrical stimulation regimen could promote axon regeneration after chronic axotomy and/or chronic denervation [5]. Indeed, we found that the electrical stimulation was very effective in promoting outgrowth of axons from chronically axotomized motor and sensory neurons, from freshly axotomized motor and sensory neurons that regenerated axons into chronically denervated nerve stumps (compare Fig. 5b and c with A), and from chronically axotomized motor and sensory neurons that regenerated their axons into chronically denervated nerve stumps (Fig. 5d), and, in turn, reinnervated their chronically denervated muscles [5].

The efficacy of the 1-h $20-\mathrm{Hz}$ electrical stimulation regimen was also demonstrated in patients who underwent carpal tunnel release surgery to promote the regeneration of injured median nerves that were severed by the constriction of the ligament at the wrist [94]. In these patients who suffered severe carpal tunnel syndrome based on several clinical and electrophysiological criteria, it was ascertained that $\sim 50 \%$ of the motor innervation of the thenar eminence was lost by Wallerian degeneration of the isolated axons distal to the lesion (Fig. 6). The numbers of innervated motor units in the thenar eminence increased gradually over a period of 1 year, but the increase was not significant with no stimulation (Fig. 6c). The patients experienced the welcomed release of pain but they were not aware of the minimal reinnervation of the muscles that move the thumb, their long flexor muscles in the forearm being effective in moving the thumb. The number of reinnervated motor units was estimated from the ratio of the compound and single all-or-none motor unit action potential amplitudes recorded in response to stimulation of all and of single nerves innervating the thenar, respectively after eminence musculature and (Fig. 6a, b). In the patients in which the nerve proximal to the carpal tunnel was subjected to brief electrical stimulation immediately after the surgical release, the number 
a. Immediate repair

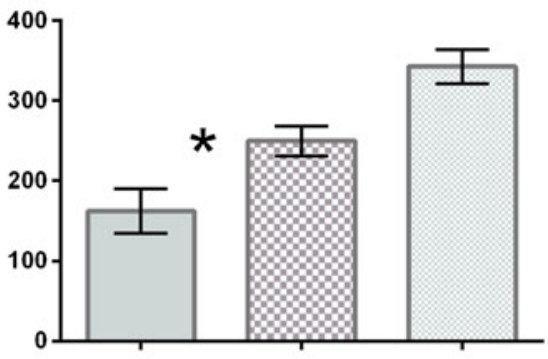

\section{b. $2 \mathrm{~m}$ chronic axotomy}

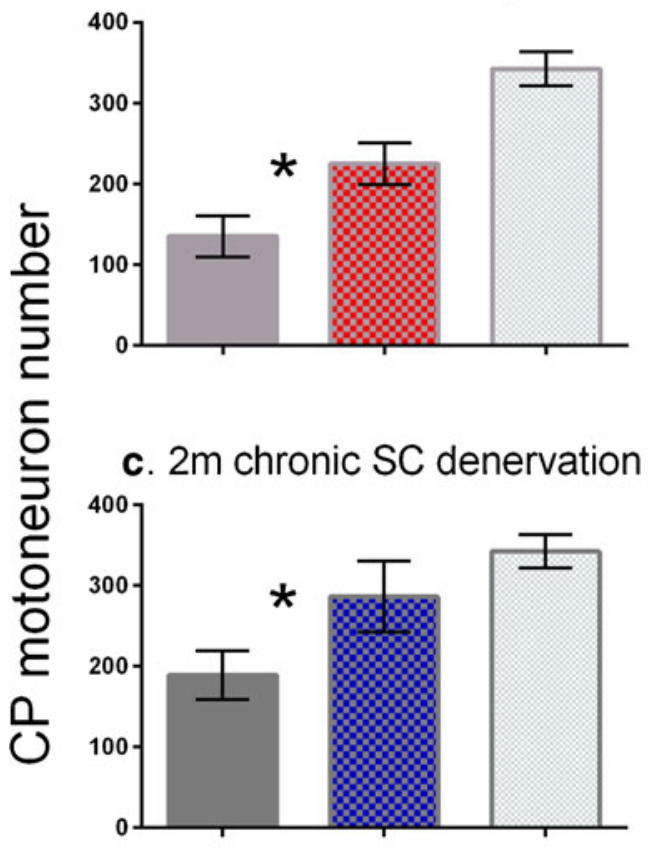

\section{d. $2 \mathrm{~m}$ chronic axotomy and SC denervation}

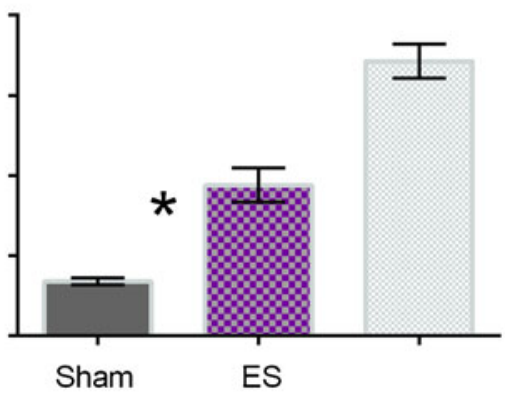

Regenerated
Intact

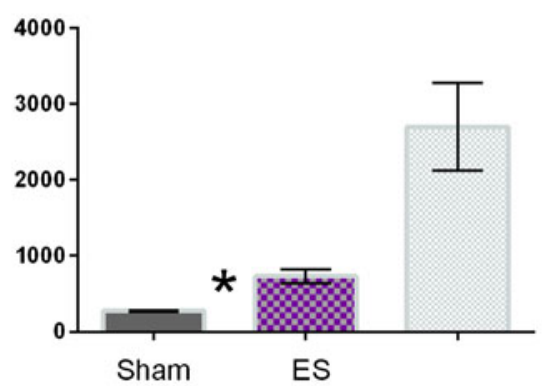

Regenerated
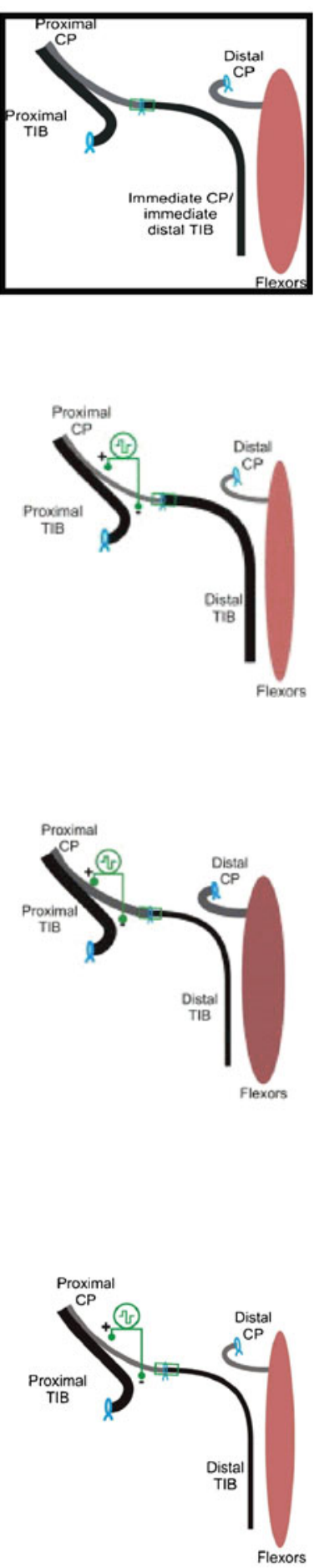

Fig. 5 Brief electrical stimulation accelerates axon outgrowth across the nerve injury site after both immediate and delayed nerve repair. Two months after cross-suture of the common peroneal (CP) proximal nerve stump and the tibial (TIB) distal nerve stump, the numbers of backlabeled $\mathrm{CP}$ motor and sensory neurons (left and right set of histograms, respectively) that regenerated their axons $10 \mathrm{~mm}$ into the TIB nerve stump was increased significantly $(* p<0.05)$ when the CP nerve proximal to the repair site was subjected to a $1-\mathrm{h}$ period of electrical stimulation after (a) immediate nerve repair, (b) 2 months $(2 \mathrm{~m})$ chronic axotomy of the CP neurons, (c) 2 months after chronic denervation of the TIB distal nerve stump, and (d) after 3 months chronic axotomy and denervation of the $\mathrm{CP}$ neurons and the distal TIB nerve stump. $\mathrm{SC}=$ Schwann cells 
of motor units increased progressively, the numbers becoming significantly larger than preoperative values within 6-8 months and all the motor axons reinnervating the musculature within the year (Fig. 6c). As these patients had demonstrated symptoms of denervation for periods of as long as 5 years prior to the release surgery, these data complement the rat data in demonstrating the brief 1-h 20 $\mathrm{Hz}$ continuous electrical stimulation is effective in promoting axon regeneration even after chronic nerve injuries.

\section{The Effect of Electrical Stimulation on Nerve Regeneration is Mimicked by Pharmacological Elevation of Cyclic Adenosine Monophosphate}

The possibility that electrical stimulation mediates its effects by elevating neuronal cyclic adenosine monophosphate (cAMP) was suggested by the early findings of improved nerve regeneration in response to pharmacological elevation of cAMP $[95,96]$. However, these findings were not replicated by others, with the authors concluding that cAMP did a

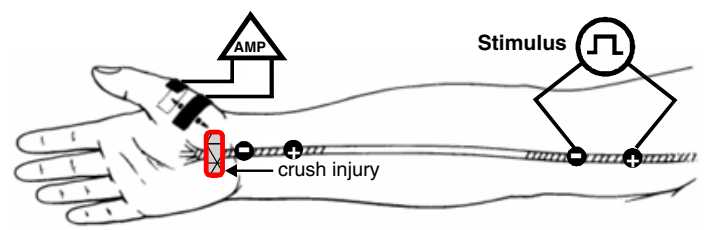

b

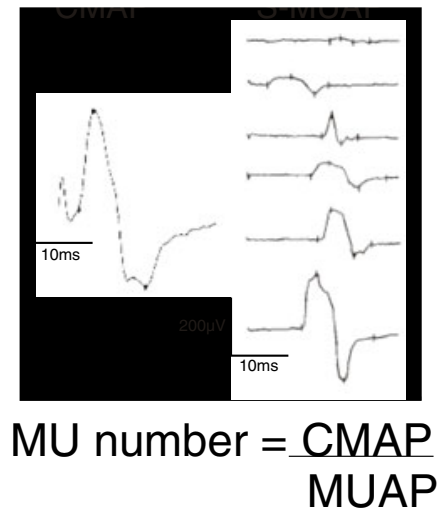

C

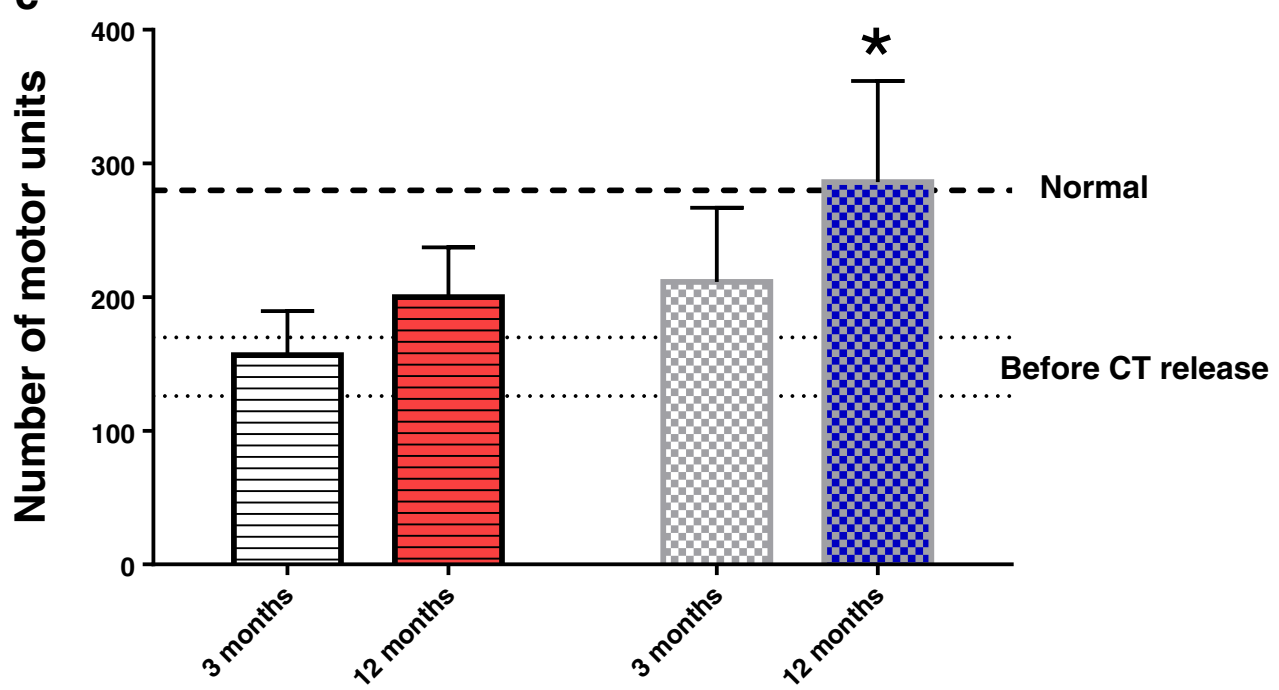

No Stimulation

Fig. 6 Brief electrical stimulation accelerates reinnervation of muscles after carpal tunnel (CT) release surgery in humans with severe CT syndrome. (a) Electromyographic (EMG) signals were recorded from surface electrodes on the thenar eminence in response to maximal and all-or-none stimulation of the median nerve. (b) The ratio of the compound action potential (CMAP) and mean motor unit potential (MUAP) provided the motor unit number estimation. Examples of MUAPs recorded in response to progressive movement of the stimulating electrodes up the arm [in (a)] are shown in (b) with the CMAP. (c) The standard errors of the mean

\section{1h $20 \mathrm{~Hz}$ Stimulation}

values before CT release (shown as dotted lines) of motor unit number before the CT release surgery demonstrate that $\sim 50 \%$ of median motoneurons were axotomized by pressure exerted by the ligament that overlies the nerve at the wrist. When the median nerve was not stimulated after the CT release surgery, the trend to increase above the preoperative number of motor units was not significant. In contrast, in those patients whose median nerve was electrically stimulated for $1 \mathrm{~h}$ continuously at $20 \mathrm{~Hz}$, the entire thenar muscle was reinnervated with restoration of the normal number of motor units (shown as an interrupted line) 
not enhance the rate of axon regeneration [55, 97, 98]. Findings that rolipram, a type IV inhibitor of the enzyme phosphodiesterase that breaks down cAMP, promoted nerve outgrowth in the CNS inspired our examination of whether local delivery of rolipram might enhance axon regeneration in the PNS [99-101]. Indeed, the rolipram infusion of
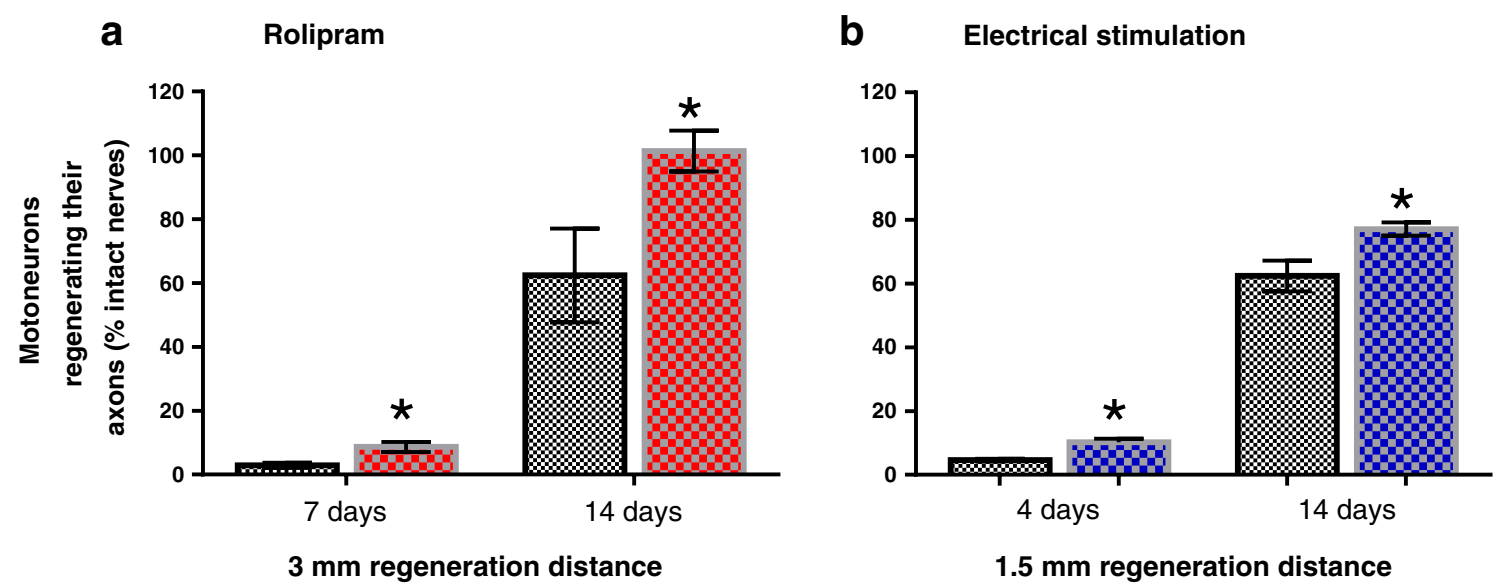

$1.5 \mathrm{~mm}$ regeneration distance

C

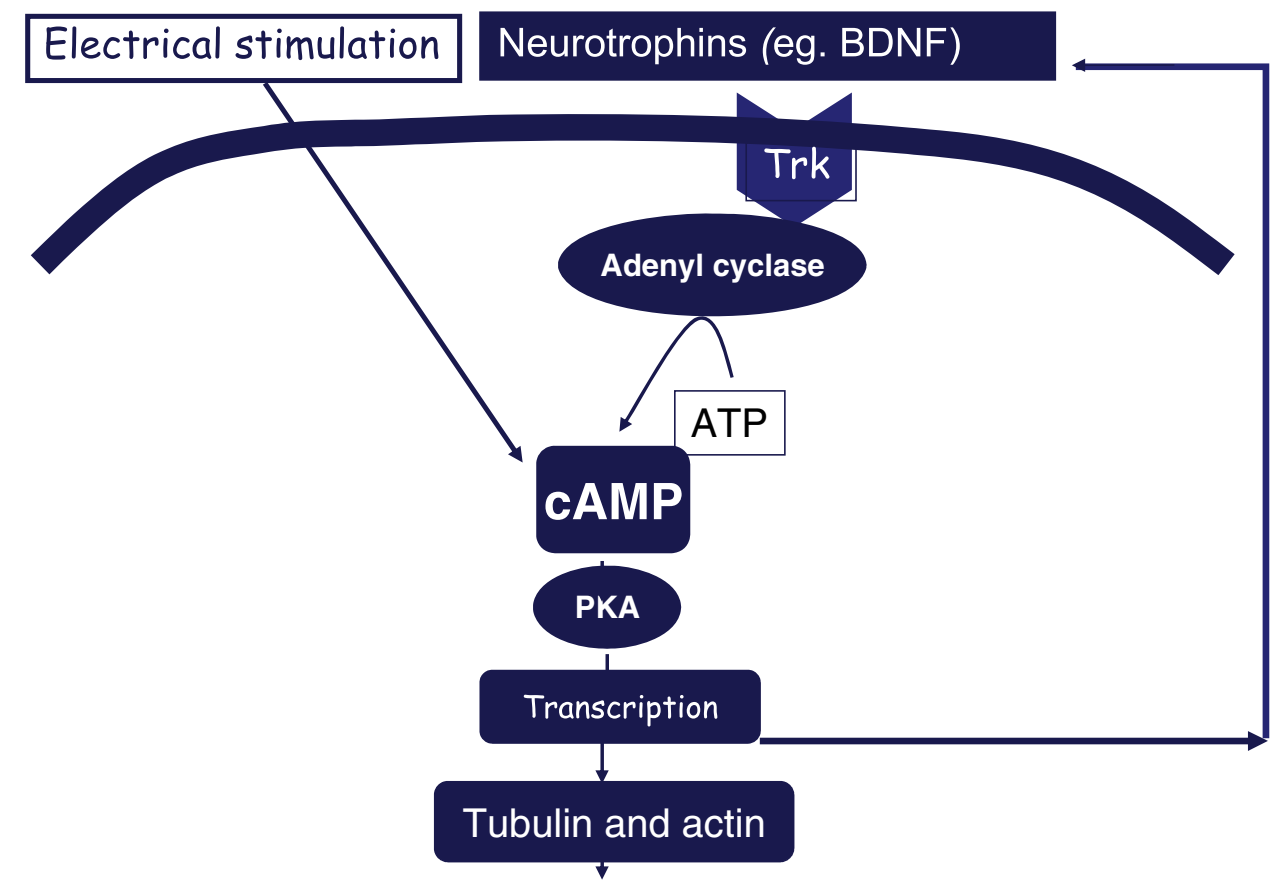

\section{AXON REGENERATION}

Fig. 7 Rolipram, a phosphodiesterase that increases intracellular cyclic adenosine monophosphate (cAMP) in neurons or brief electrical stimulation accelerates axon outgrowth across the suture line of a transected and surgically repaired peripheral nerve in rats. (a) Rolipram administered locally to a surgically repaired common peroneal nerve or (b) $1 \mathrm{~h}$ continuous $20-\mathrm{Hz}$ electrical stimulation proximal to the surgical repair site of a transected femoral nerve significantly increases the number of the surgical site via a miniosmotic pump accelerated axon outgrowth across the surgical suture site and into the distal nerve stump in an analogous manner to the effect of the electrical stimulation in accelerating femoral motoneurons to regenerate their axons across the surgical repair site (Fig. 7a, b). Pharmacological elevation of cAMP in cultured

motoneurons that regenerate their axons. (c) Protein kinase A is activated by cAMP to promote transcription of proteins that include the neurotrophic factors that amplify the effects of cAMP in promoting gene transcription of growth associated genes such as tubulin and actin and, in turn, accelerate axon outgrowth $(p<0.05) . \mathrm{BDNF}=$ brain-derived neurotrophic factor; $\mathrm{ATP}=$ adenosine triphosphate $\mathrm{PKA}=$ protein kinase $\mathrm{A}$ 
motoneurons was also effective in promoting neurite outgrowth [102].

\section{Brief Electrical Stimulation Accelerates Axon Outgrowth Within the CNS}

The analogous growth promoting effects of brief lowfrequency electrical stimulation and rolipram-induced elevation of neuronal cAMP in the PNS suggested that the electrical stimulation paradigm might also promote nerve outgrowth in the CNS. Indeed, Woolf and colleagues had demonstrated that elevated cAMP in dorsal root ganglion neurons was responsible for the efficacy of a conditioning lesion to the sensory axons in the PNS in promoted outgrowth from transected central axons [103]. The efficacy of the conditioning lesion in promoting regeneration of CNS axons was first demonstrated in 1984 [104]. Because sensory neurons discharge at rates up to $200 \mathrm{~Hz}$, we compared the efficacy of a 1-h period of continuous $200-$ and $20-\mathrm{Hz}$ electrical stimulation applied to the sciatic nerve immediately after cutting the central axons at the level of T8 in the spinal cord [86]. The $20-\mathrm{Hz}$ electrical stimulation paradigm but not the $200-\mathrm{Hz}$ electrical stimulation paradigm promoted the outgrowth of CNS sensory axons at the level of T8, although to a lesser extent than the conditioning lesion (Fig. 8). This outgrowth was associated with a significant elevation in cAMP in the neurons that were stimulated at $20 \mathrm{~Hz}$ but not at $200 \mathrm{~Hz}$, the elevation being the same as after the conditioning lesion. The discrepancy between the elevated cAMP and the efficacy of the electrical stimulation in promoting axon outgrowth suggested additional mechanisms to account for the greater effect of the conditioning lesion than the electrical stimulation [86].

The suppressed ability of axotomized sensory neurons to upregulate growth-associated proteins (GAPs) when their central axons are injured is 1 of the 2 reasons why the axons do not normally regrow their lost axons, the other being the presence of the oligodendrocytes rather than Schwann cells in the CNS and the proteoglycans that directly inhibit axon extension [105-108]. Only when GAPs are expressed as they are after proximal CNS nerve lesions for example, do the CNS axons regrow $[109,110]$. The expression of both GAP-43 and CAP-23, members of a MARCKs-related group of acylated membrane proteins that interact with actin filaments, calmodulin, protein kinase $\mathrm{C}$, and phophoinositides, is prerequisite for CNS nerve regeneration, regeneration occurring only when both proteins are expressed in the injured neurons [111]. Electrical stimulation promoted axon outgrowth in the CNS but the contrasting efficacy of a conditioning lesion to promote both axon outgrowth and extension of the regenerating axons in the spinal cord indicates that electrical stimulation failed to upregulate both GAPs (Fig. 8).

\section{The Role of Neurotrophic Factors and Androgens in the Efficacy of Electrical Stimulation, and Daily Exercise Programs in Promoting Axon Regeneration in the PNS}

Brief electrical stimulation accelerates the expression of neurotrophic factors and their receptors [6]. Thereafter, the cytoskeletal proteins actin and tubulin, and GAP-43 are upregulated (Fig. 7c) [7]. Using transgenic mice that express yellow fluorescent protein in a small proportion of their axons and by cross-breeding of these mice with mice in which neurotrophic factor expression was deleted, English et al. [66] demonstrated the critical role of the neurotrophic factors brainderived neurotrophic factor (BDNF) and neurotrophin $4 / 5$ in the efficacy of the electrical stimulation effect in accelerating nerve regeneration [66]. Exogenous administration of either BDNF or GDNF did not increase nerve regeneration after immediate nerve repair (Fig. 9) [9, 10]; however, after a period of chronic axotomy before cross-suturing the proximal tibial nerve stump to a freshly denervated common peroneal distal nerve stump, the administration of either factor alone or together did significantly increase the number of motoneurons that regenerated their axons (Fig. 9c). Normally there is sufficient expression of neurotrophic factors in the neurons and the Schwann cells after nerve injury to sustain nerve regeneration [35]; however, after chronic axotomy, exogenous sources of BDNF and/or GDNF were necessary to promote nerve regeneration (Fig. 9a-c). In contrast to GDNF that acts via its receptors to promote axon regeneration, BDNF has a bimodal effect with low doses acting via trkB receptors to promote axon regeneration, while high doses act via p75 to inhibit axonal regeneration [8-10].

Although GDNF has been shown to be efficacious when applied in microspheres around the suture site of injured peripheral nerves with and without an intervening acellular conduit [112-118], the difficulties of titrating effective doses of BDNF illustrate some of the difficulties that may be encountered with exogenous sources of the neurotrophic factors. The biological modulation of the neurotrophic factors is difficult to replicate and problems of excess administration have been described, as, for example, the administration of excess doses of GDNF using retroviral vectors in rats where the findings of axonal coils was attributed to too much GDNF $[119,120]$.

While electrical stimulation upregulates the expression of neurotrophic factors and their receptors, this expression is transient, declining within days [6]. The administration of androgens in conjunction with electrical stimulation, however, sustains their upregulation $[81,82]$. Over the course of evaluating the extent of activity-mediated axonal regeneration, Sabatier et al. [121] and Wood et al. [122] discovered a sex difference in the effectiveness of treadmill training when comparing 2 treadmill training paradigms, continuous and interval training. A daily slow training protocol at $10 \mathrm{~m} / \mathrm{min}$ 
i.
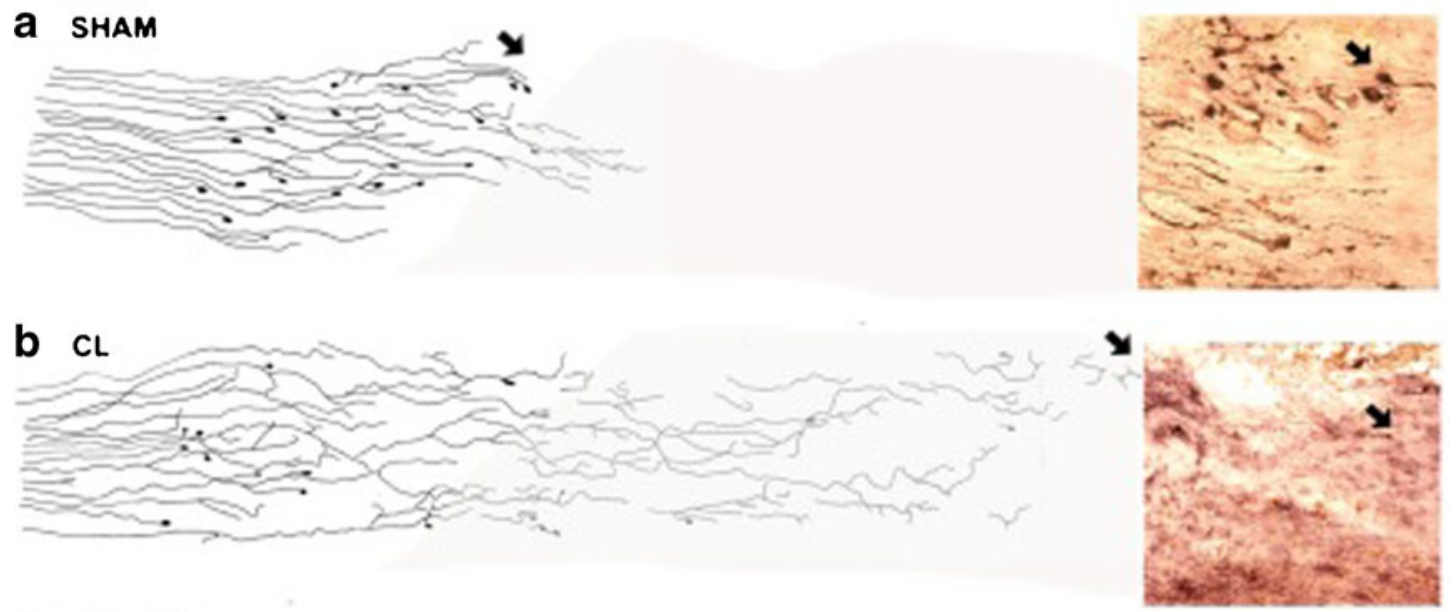

\section{C $20 \mathrm{~Hz}$ ES}

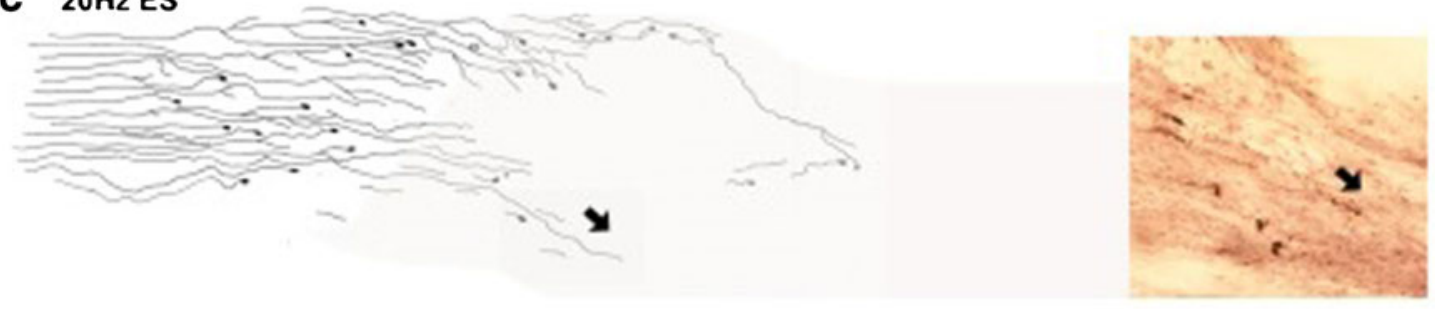

ii.
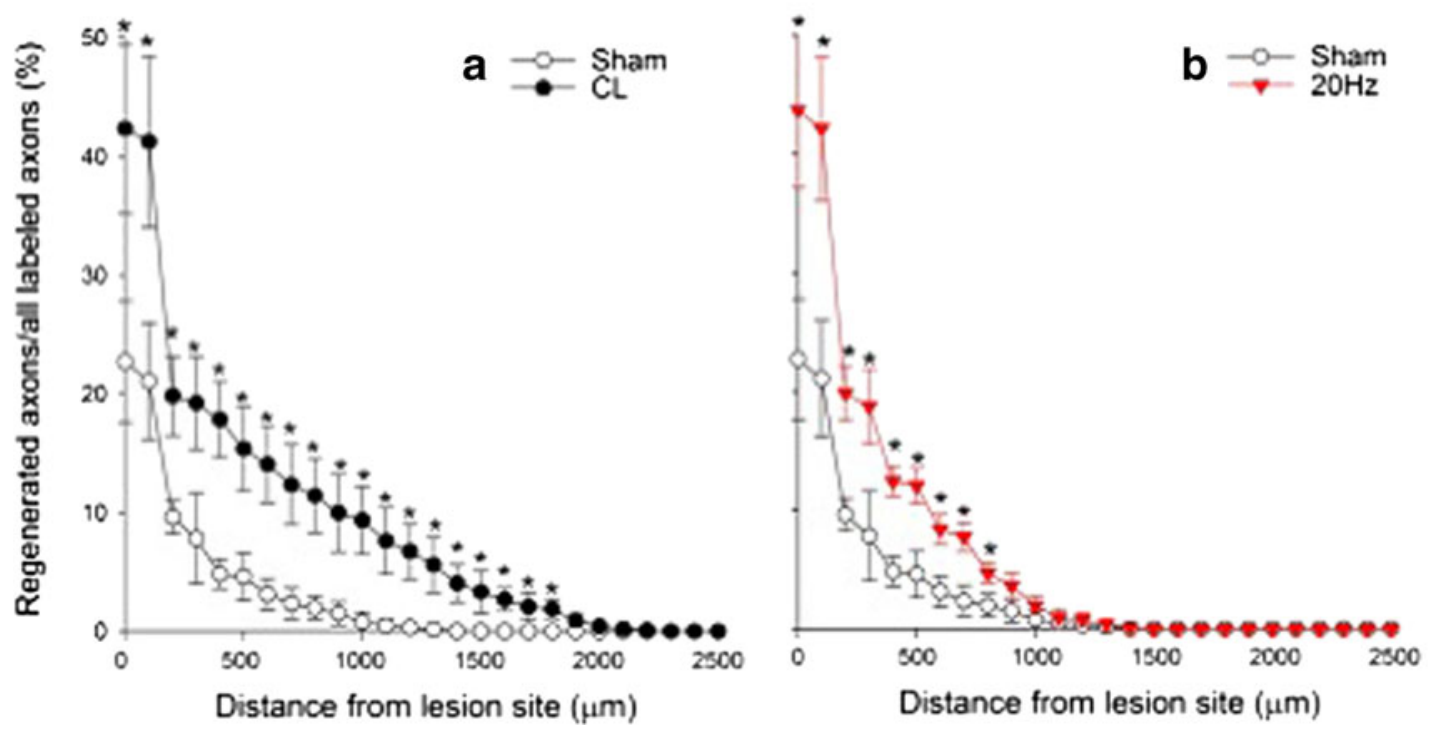

Fig. 8 A conditioning lesion and brief electrical stimulation (ES) promotes nerve regeneration within the spinal cord. (ia) Following a spinal lesion at the level of T8, few axons entered the lesion site [camara lucida drawings with example of cholerotoxin (CTX)-stained axons 1 week after injecting CTX into the sciatic nerve] after sham electrical stimulation at $20 \mathrm{~Hz}$ for $1 \mathrm{~h}$ (or a sham conditional lesion, not shown). (ib) In contrast, a conditioning sciatic crush lesion (CL) resulted in more regeneration of

for $1 \mathrm{~h}$ resulted in a marked increase in the length of regenerating axons in male mice 2 weeks after nerve transection and repair, but the protocol had no effect on regeneration in female mice $[85,122]$. On the other hand, when

CTX-labeled axons, with (ic) an intermediate number regenerating after $1 \mathrm{~h}$ of $20-\mathrm{Hz}$ continuous electrical stimulation of the sciatic nerve. (iia) The significantly $(p<0.05)$ elevated number of regenerated sciatic nerve axons that grew out and over longer distances from the lesion site after a $\mathrm{CL}$ and (iib) the significantly elevated numbers of axons that grew out from the lesion site but did not grow over longer distances after $20 \mathrm{~Hz}$ electrical stimulation for $1 \mathrm{~h}$. Each point is the mean \pm SEM

the female mice were exposed to a faster $20 \mathrm{~m} / \mathrm{min}$ training protocol for 2-min intervals 4 times daily, an impressive enhancement in axonal regeneration was seen. No enhancement was appreciated in the male mice exposed to the same 
a

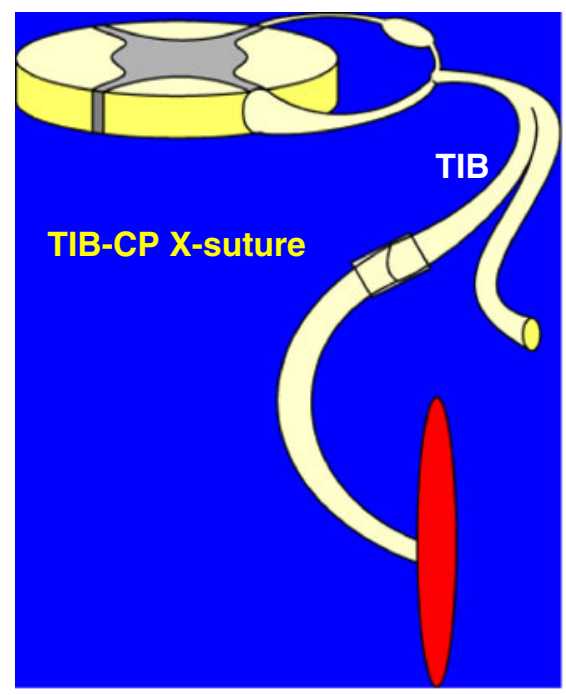

b

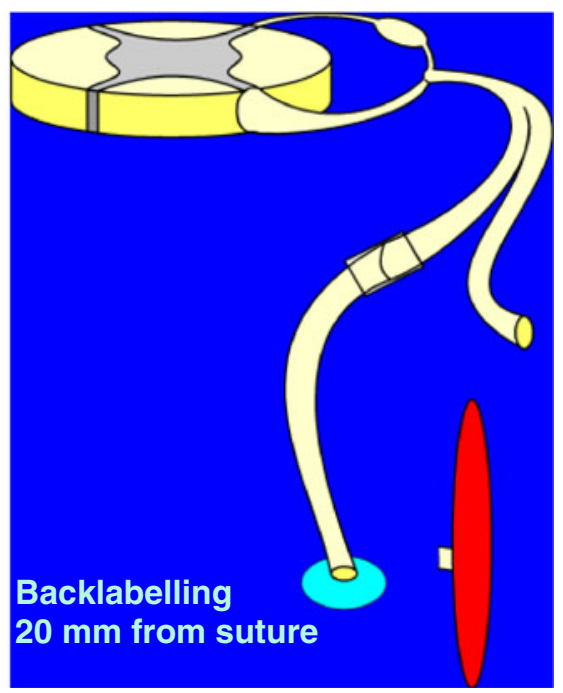

\section{C}

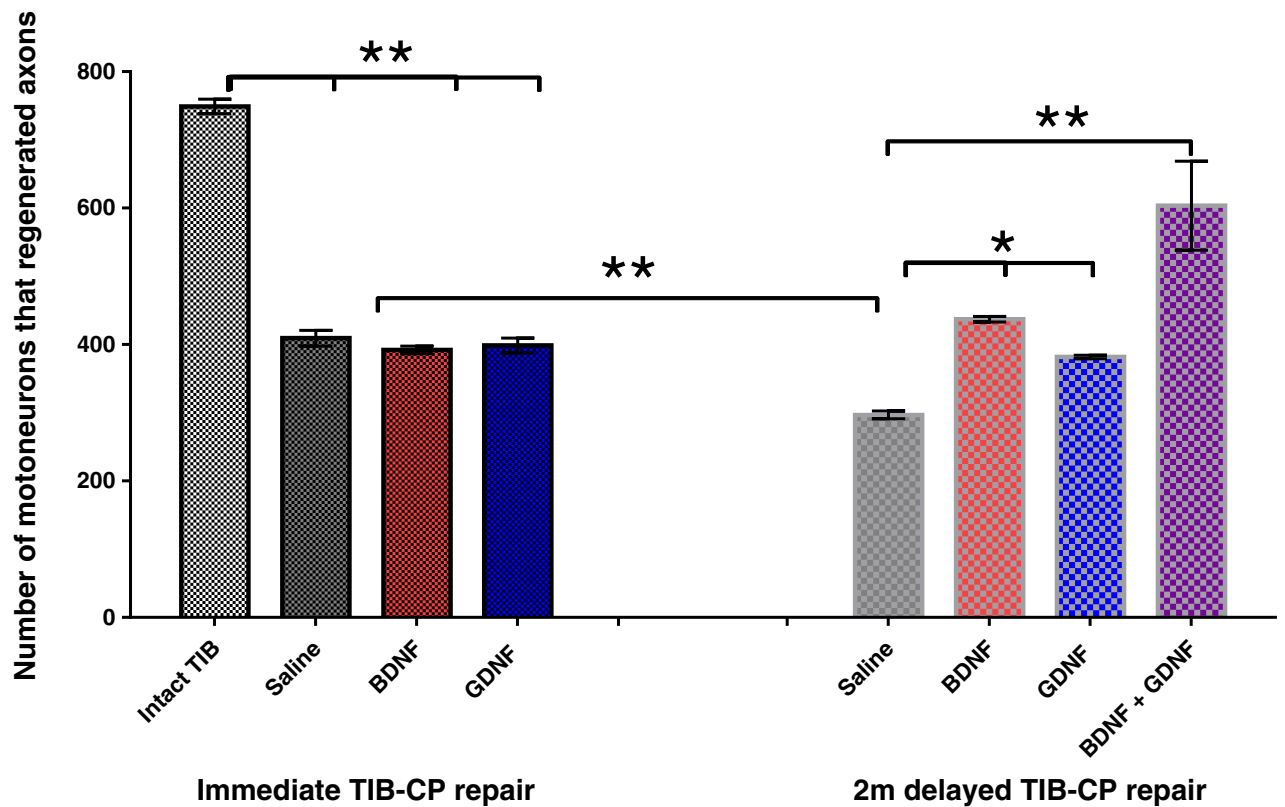

Fig. 9 Exogenous administration of the neurotrophic factors brainderived neurotrophic factor (BDNF) and glial cell-line derived neurotrophic factor (GDNF) promotes neuronal regeneration of injured motoneurons after delayed nerve repair. (a) A cross-suture (X-suture) technique to cross-suture the freshly cut tibial (TIB) proximal nerve stump to the distal stump of the freshly cut common peroneal (CP) nerve or to cross-suture the TIB proximal nerve stump that was ligated for 2 months ( $2 \mathrm{~m}$ ) previously (to prolong TIB motoneuron axotomy) to a freshly cut $\mathrm{CP}$ distal nerve stump. The neurotrophic factors were delivered from a miniosmotic pump to the coaptation site over a 1-month period. (b) Thereafter, the regenerated TIB axons in the CP nerve were exposed to

interval training protocol. The studies from English's laboratory provide evidence that sex steroid hormones, particularly testosterone, mediate this sex difference in exercised mice [122]. They also demonstrate that androgens are also fluorogold to backlabel those TIB motoneurons that regenerated their axons over a $20-\mathrm{mm}$ distance. (c) Saline-treated axons regenerated $\sim 45 \%$ of their axons within the a month of regeneration, consistent with the staggered regeneration demonstrated by Al-Majed et al. [6]. This regeneration was significantly reduced by a 2 -month period of chronic axotomy consistent with the data of $\mathrm{Fu}$ and Gordon [17]. The decline in motoneuron numbers after 2 months was not only prevented by a month of administration of BDNF ( $2 \mu \mathrm{g}$ /day) or GDNF $(0.1 \mu \mathrm{g} /$ day $)$, but also the neurotrophic factors significantly increased the numbers of 2-month chronically axotomized motoneurons that regenerated their axons (* $p<0.05 ; * * p<0.01$ )

critical for the efficacy of low-frequency electrical stimulation in promoting axon outgrowth [85]. In the former case, castration of male rats eliminated the enhanced axon regeneration by daily interval training, and treating unexercised 
female mice with an aromatase inhibitor, anastrozole, to block the conversion of testosterone or its precursors into estradiol, enhanced axonal regeneration [122]. Subsequent experiments demonstrated that treating mice with flutamide, an androgen receptor blocker, inhibited the effect of both exercise and electrical stimulation in both sexes [85]. As treadmill training can be readily applied to humans, the translational potential of this modality in combination with electrical stimulation in peripheral nerve injuries is promising, while activity-dependent therapies also simultaneously empower patients to assume responsibility for their own recovery.

\section{Conclusions}

The sluggish crossing of regenerating axons across injury sites, whether or not the endoneurial tubes are disrupted by transection of peripheral nerves, compounds the problems of the slow rate of axon regeneration of $1 \mathrm{~mm} /$ day in humans and of $3 \mathrm{~mm} /$ day in animals $[3,123]$. As a result, functional recovery after nerve injuries is commonly recognized to be disappointing [124]. The efficacy of brief low-frequency electrical stimulation in accelerating axon outgrowth across the injury site in both animal and human studies results in accerelated and improved functional recovery. This improvement was demonstrated in a number of published and ongoing studies of human nerve injuries [94, 125, and Chan, unpublished data]. Importantly, the electrical stimulation regimen is effective after delayed nerve repair in animals and humans [5, 94]. These very promising findings anticipate further studies that may form the basis for the adoption of technique of intraoperative brief electrical stimulation at the time of surgical repair of injured nerves to become the standard of practice in management of peripheral nerve injuries. The ability of training programs after surgical repair of peripheral nerves to accelerate nerve regeneration in animal studies also holds considerable promise for the management of peripheral nerve injuries [85, 122]. Whilst movement is usually restricted after surgical repair of injured nerves, possibilities such as the adoption of imagined movement in the early stages of recovery followed by adoption of active programs of activity may be explored in the future.

Finally, there are several other surgical and pharmacological strategies that are being explored to promote regeneration and to counteract the negative effects of chronic nerve injuries [126]. These include the placement of end-to-side or side-toside nerve autografts between a donor nerve and a recipient denervated distal nerve stump [14, 127], and the localized administration of FK506 and neurotrophic factors to the surgical site [11]. In the former case, the ingrowth of axons into a denervated nerve stump that proceeds both proximal and distal to the insertion site of the autograft into the recipient denervated stump significantly improves the regeneration of axons after surgical coaptation of the proximal and distal nerve stumps through the distal nerve stump into which the donor axons had grown. Local administration of FK506 to the coaptation site of a transected nerve was also very effective in promoting nerve regeneration. Hence, a combinational approach to surgical repair of transected nerves has enormous potential for greatly improving nerve regeneration and, in turn, functional recovery after peripheral nerve injuries.

Acknowledgments I thank all my colleagues who contributed to the several published papers that are included in this review, and the Canadian Institutes of Research who provided the grant funding to carry out the work published in the papers.

Compliance with Ethical Standards Required Author Forms Disclosure forms provided by the authors are available with the online version of this article.

\section{References}

1. Fenrich K, Gordon T. Canadian Association of Neuroscience review: axonal regeneration in the peripheral and central nervous systems-current issues and advances. Neurol Sci 2004;31:142156.

2. Fu SY, Gordon T. The cellular and molecular basis of peripheral nerve regeneration. Mol Neurobiol 1997;14:67-116.

3. Brushart TM, Hoffman PN, Royall RM, Murinson BB, Witzel C, Gordon T. Electrical stimulation promotes motoneuron regeneration without increasing its speed or conditioning the neuron. $\mathrm{J}$ Neurosci 2002;22:6631-38.

4. Al-Majed AA, Neumann CM, Brushart TM, Gordon T. Brief electrical stimulation promotes the speed and accuracy of motor axonal regeneration. J Neurosci 2000;20:2602-2608.

5. Elzinga K, Tyreman N, Ladak A, Savaryn B, Olson J, Gordon T. Brief electrical stimulation improves nerve regeneration after delayed repair in Sprague Dawley rats. Exp Neurol 2015;269:142153.

6. Al-Majed AA, Brushart TM, Gordon T. Electrical stimulation accelerates and increases expression of BDNF and trkB mRNA in regenerating rat femoral motoneurons. Eur J Neurosci 2000;12: 4381-4390.

7. Al-Majed AA, Tam SL, Gordon T. Electrical stimulation accelerates and enhances expression of regeneration-associated genes in regenerating rat femoral motoneurons. Cell Mol Neurobiol 2004:24:379-402.

8. Boyd JG, Gordon T. The neurotrophin receptors, trkB and $\mathrm{p} 75$, differentially regulate motor axonal regeneration. J Neurobiol 2001;49:314-325.

9. Boyd JG, Gordon T. A dose-dependent facilitation and inhibition of peripheral nerve regeneration by brain-derived neurotrophic factor. Eur J Neurosci 2002;15:613-626.

10. Boyd JG, Gordon T. Glial cell line-derived neurotrophic factor and brain-derived neurotrophic factor sustain the axonal regeneration of chronically axotomized motoneurons in vivo. Exp Neurol 2003; 183:610-619.

11. Tajdaran K. Enhancement of peripheral nerve regeneration with controlled release of glial cell line-derived neurotrophic factor (GDNF). MSc thesis, University of Toronto, 2015.

12. Willand MP, Chiang CD, Zhang JJ, Kemp SW, Borschel GH, Gordon T. Daily electrical muscle stimulation enhances functional recovery following nerve transection and repair in rats. Neurorehabil Neural Repair 2015;29:690-700. 
13. Ladak A, Tyreman N, Schembri P, Udina E, Olson J, Gordon T. Application of side-to-side nerve grafts to sustain chronically denervated nerve pathways and in turn, to encourage axon regeneration and improved reinnervation [abstract]. Sunderland Society 2009; 19 .

14. Gordon T, Hendry M, Lafontaine CA, Cartar H, Zhang JJ, Borschel GH. Nerve cross-bridging to enhance nerve regeneration in a rat model of delayed nerve repair. PLoS ONE 2015;10: e0127397.

15. Hendry JM, Alvarez-Veronesi MC, Snyder-Warwick A, Gordon T, Borschel GH. Side-to-side nerve bridges support donor axon regeneration into chronically denervated nerves and are associated with characteristic changes in Schwann cell phenotype. Neurosurgery 2015;77:803-813.

16. Wood MD, Kemp SW, Weber C, Borschel GH, Gordon T. Outcome measures of peripheral nerve regeneration. Ann Anat 2011;193:321-333.

17. Fu SY, Gordon T. Contributing factors to poor functional recovery after delayed nerve repair: prolonged axotomy. J Neurosci 1995; 15:3876-3885.

18. Abercrombie M, Johnson ML. Quantitative histology of Wallerian degeneration 1). Nuclear population in rabbit sciatic nerve. J Anat 1946;80:37-50

19. Beuche W, Friede RL. The role of non-resident cells in Wallerian degeneration. J Neurocytol 1984;13:767-796.

20. Scheidt P, Friede RL. Myelin phagocytosis in Wallerian degeneration. Properties of millipore diffusion chambers and immunohistochemical identification of cell populations. Acta Neuropathol 1987;75:77-84

21. Stoll G, Griffin JW, Li CY, Trapp BD. Wallerian degeneration in the peripheral nervous system: participation of both Schwann cells and macrophages in myelin degradation. J Neurocytol 1989;18: 671-683.

22. Bruck W. The role of macrophages in Wallerian degeneration. Brain Pathol 1997;7:741-752.

23. Stoll G, Muller HW. Nerve injury, axonal degeneration and neural regeneration: basic insights. Brain Pathol 1999;9:313-325.

24. Gaudet AD, Popovich PG, Ramer MS. Wallerian degeneration: gaining perspective on inflammatory events after peripheral nerve injury. J Neuroinflammation 2011;8:110.

25. Gordon T. The biology, limits, and promotion of peripheral nerve regeneration in rats and human. Nerves And Nerve Injuries Eds: Tubbs RS, Rizk E, Shoja M, Loukas M, and Spinner RJ. Elsevier, 2015, Vol. 2 Ch 61, pp. 993-1019.

26. Cajal SR. Degeneration and regeneration of the nervous system (RM May, transl.). Oxford University Press, New York, 1928.

27. Webber C, Zochodne D. The nerve regenerative microenvironment: Early behavior and partnership of axons and Schwann cells. Exp Neurol 2010;223:51-59.

28. Gordon T, English AW. Strategies to promote peripheral nerve regeneration: electrical stimulation and/or exercise. Eur J Neurosci 2015, pp1-15 [Epub ahead of print].

29. Fu SY, Gordon T. Contributing factors to poor functional recovery after delayed nerve repair: prolonged denervation. J Neurosci 1995; 15:3886-3895.

30. Sulaiman OAR, Gordon T. Effects of short- and long-term Schwann cell denervation on peripheral nerve regeneration, myelination, and size. Glia 2000;32:234-246.

31. Hoke A, Gordon T, Zochodne DW, Sulaiman OAR. A decline in glial cell-line-derived neurotrophic factor expression is associated with impaired regeneration after long-term Schwann cell denervation. Exp Neurol 2002;173:77-85.

32. Sulaiman OAR, Voda J, Gold BG, Gordon T. FK506 increases peripheral nerve regeneration after chronic axotomy but not after chronic Schwann cell denervation. Exp Neurol 2002;175:127137
33. Sulaiman OAR, Gordon T. Transforming growth factor-beta and forskolin attenuate the adverse effects of long-term Schwann cell denervation on peripheral nerve regeneration in vivo. Glia 2002;37:206-218.

34. Gordon T, Sulaiman OAR, Boyd JG. Experimental strategies to promote functional recovery after peripheral nerve injuries. J Peripher Nerv Syst 2003;8:236-250.

35. Furey MJ, Midha R, Xu QG, Belkas J, Gordon T. Prolonged target deprivation reduces the capacity of injured motoneurons to regenerate. Neurosurgery 2007;60:723-732.

36. Gordon T, Tyreman N, Raji MA. The basis for diminished functional recovery after delayed peripheral nerve repair. J Neurosci 2011;31:5325-5334.

37. Rafuse VF, Gordon T, Orozco R. Proportional enlargement of motor units after partial denervation of cat triceps surae muscles. J Neurophysiol 1992;68:1261-1275.

38. Gordon T, Stein RB. Time course and extent of recovery in reinnervated motor units of cat triceps surae muscles. J Physiol 1982;323:307-323

39. You S, Petrov T, Chung PH, Gordon T. The expression of the low affinity nerve growth factor receptor in long-term denervated Schwann cells. Glia 1997;20:87-100.

40. Boyd JG, Gordon T. Neurotrophic factors and their receptors in axonal regeneration and functional recovery after peripheral nerve injury. Mol Neurobiol 2003;27:277-324.

41. Brushart TM, Aspalter M, Griffin JW, et al. Schwann cell phenotype is regulated by axon modality and central-peripheral location, and persists in vitro. Exp Neurol 2013;247C:272-281.

42. Hoke A, Redett R, Hameed H, et al. Schwann cells express motor and sensory phenotypes that regulate axon regeneration. J Neurosci 2006;26:9646-9655.

43. McGraw J, McPhail LT, Oschipok LW, et al. Galectin-1 in regenerating motoneurons. Eur J Neurosci 2004;20:2872-2880.

44. Bisby MA, Tetzlaff W. Changes in cytoskeletal protein synthesis following axon injury and during axon regeneration. Mol Neurobiol 1992;6:107-123.

45. Tetzlaff W, Alexander SW, Miller FD, Bisby MA. Response of facial and rubrospinal neurons to axotomy: changes in mRNA expression for cytoskeletal proteins and GAP-43. J Neurosci 1991;11:2528-2544.

46. Tetzlaff W, Bisby MA, Kreutzberg GW. Changes in cytoskeletal proteins in the rat facial nucleus following axotomy. J Neurosci 1988;8:3181-3189.

47. Eggers R, Tannemaat MR, Ehlert EM, Verhaagen J. A spatiotemporal analysis of motoneuron survival, axonal regeneration and neurotrophic factor expression after lumbar ventral root avulsion and implantation. Exp Neurol 2010;223:207-220.

48. Gordon T, You S, Cassar SL, Tetzlaff W. Reduced expression of regeneration associated genes in chronically axotomized facial motoneurons. Exp Neurol 2014;264:26-32.

49. Mi R, Chen W, Hoke A. Pleiotrophin is a neurotrophic factor for spinal motor neurons. Proc Natl ACad Sci 2007;104:4664-4669.

50. Gutmann E, Guttmann L, Medawar PB, Young JZ. The rate of regeneration of nerve. J Exp Biol 1942;19:14-44.

51. Sunderland S. Rate of regeneration of motor fibers in the ulnar and sciatic nerves. Arch Neurol Psychiatry 1947;58:7-13.

52. Sunderland S. Rate of regeneration of sensory nerve fibers. Arch Neurol Psychiatry 1947;58:1-5.

53. Sunderland S. Rate of regeneration in human peripheral nerves: analysis of interval between injury and onset of recovery. Arch Neurol Psychiat 1947;58:251-295.

54. Danielsen N, Lundborg G, Frizell M. Nerve repair and axonal transport: outgrowth delay and regeneration rate after transection and repair of rabbit hypoglossal nerve. Brain Res 1986;376:125132. 
55. Black MM, Lasek RJ. Slowing of the rate of axonal regeneration during growth and maturation. Exp Neurol 1979;63:108-119.

56. Witzel C, Rohde C, Brushart TM. Pathway sampling by regenerating peripheral axons. J Comp Neurol 2005;485:183-190.

57. Nix WA, Hopf HC. Electrical stimulation of regenerating nerve and its effect on motor recovery. Brain Res 1983;272:21-25.

58. Pockett S, Gavin RM. Acceleration of peripheral nerve regeneration after crush injury in rat. Neurosci Lett 1985;59:221-224.

59. Geremia NM, Gordon T, Brushart TM, Al-Majed AA, Verge VM. Electrical stimulation promotes sensory neuron regeneration and growth-associated gene expression. Exp Neurol 2007;205:347359

60. Ahlborn P, Schachner M, Irintchev A. One hour electrical stimulation accelerates functional recovery after femoral nerve repair. Exp Neurol 2007;208:137-144.

61. Alrashdan MS, Park JC, Sung MA, et al. Thirty minutes of low intensity electrical stimulation promotes nerve regeneration after sciatic nerve crush injury in a rat model. Acta Neurol Belg 2010;110:168-179.

62. Alrashdan MS, Sung MA, Kwon YK, Chung HJ, Kim SJ, Lee JH. Effects of combining electrical stimulation with BDNF gene transfer on the regeneration of crushed rat sciatic nerve. Acta Neurochir (Wien) 2011;153:2021-2029.

63. Asensio-Pinilla E, Udina E, Jaramillo J, Navarro X. Electrical stimulation combined with exercise increase axonal regeneration after peripheral nerve injury. Exp Neurol 2009;219:258-265.

64. Beaumont E, Cloutier FC, Atlan M, Rouleau DM, Beaumont PH. Chondroitinase $\mathrm{ABC}$ and acute electrical stimulation are beneficial for muscle reinnervation after sciatic nerve transection in rats. Restor Neurol Neurosci 2009;27:297-305.

65. Cavalcante Miranda de AD, Martins LE, Teixeira GB, et al. The parameters of transcutaneous electrical nerve stimulation are critical to its regenerative effects when applied just after a sciatic crush lesion in mice. Biomed Res Int 2014;2014:572949.

66. English AW, Schwartz G, Meador W, Sabatier MJ, Mulligan A. Electrical stimulation promotes peripheral axon regeneration by enhanced neuronal neurotrophin signaling. Dev Neurobiol 2007;67:158-172.

67. Foecking EM, Fargo KN, Coughlin LM, Kim JT, Marzo SJ, Jones KJ. Single session of brief electrical stimulation immediately following crush injury enhances functional recovery of rat facial nerve. J Rehabil Res Dev 2012;49:451-458.

68. Franz CK, Rutishauser U, Rafuse VF. Intrinsic neuronal properties control selective targeting of regenerating motoneurons. Brain 2008;131:1492-1505.

69. Haastert-Talini K, Schmitte R, Korte N, Klode D, Ratzka A, Grothe $\mathrm{C}$. Electrical stimulation accelerates axonal and functional peripheral nerve regeneration across long gaps. J Neurotrauma 2011;28:661-674.

70. Haastert-Talini K, Grothe C. Electrical stimulation for promoting peripheral nerve regeneration. Int Rev Neurobiol 2013;109:111-124.

71. Hetzler LE, Sharma N, Tanzer L, et al. Accelerating functional recovery after rat facial nerve injury: Effects of gonadal steroids and electrical stimulation. Otolaryngol Head Neck Surg 2008;139: 62-67.

72. Huang J, Hu X, Lu L, Ye Z, Zhang Q, Luo Z. Electrical regulation of Schwann cells using conductive polypyrrole/chitosan polymers. J Biomed Mater Res A 2010;93:164-174.

73. Huang $\mathrm{J}, \mathrm{Lu} \mathrm{L}, \mathrm{Hu} \mathrm{X}$, et al. Electrical stimulation accelerates motor functional recovery in the rat model of $15-\mathrm{mm}$ sciatic nerve gap bridged by scaffolds with longitudinally oriented microchannels. Neurorehabil Neural Repair 2010;24:736-745.

74. Huang J, Lu L, Zhang J, et al. Electrical stimulation to conductive scaffold promotes axonal regeneration and remyelination in a rat model of large nerve defect. PLoS ONE 2012;7:e39526.
75. Koppes AN, Zaccor NW, Rivet CJ, et al. Neurite outgrowth on electrospun PLLA fibers is enhanced by exogenous electrical stimulation. J Neural Eng 2014;11:046002.

76. Lu MC, Ho CY, Hsu SF, et al. Effects of electrical stimulation at different frequencies on regeneration of transected peripheral nerve. Neurorehabil Neural Repair 2008;22:367-373.

77. McDevitt L, Fortner P, Pomeranz B. Application of weak electric field to the hindpaw enhances sciatic motor nerve regeneration in the adult rat. Brain Res 1987;416:308-314.

78. Monaco GN, Brown TJ, Burgette RC, et al. Electrical stimulation and testosterone enhance recovery from recurrent laryngeal nerve crush. Restor Neurol Neurosci 2015;33:571-578.

79. Rozman J, Zorko B, Seliskar A. Regeneration of the radial nerve in a dog influenced by electrical stimulation. Pflugers Arch 2000;439:R184-R186.

80. Sharma N, Coughlin L, Porter RG, et al. Effects of electrical stimulation and gonadal steroids on rat facial nerve regenerative properties. Restor Neurol Neurosci 2009;27:633-644.

81. Sharma N, Moeller CW, Marzo SJ, Jones KJ, Foecking EM. Combinatorial treatments enhance recovery following facial nerve crush. Laryngoscope 2010;120:1523-1530.

82. Sharma N, Marzo SJ, Jones KJ, Foecking EM. Electrical stimulation and testosterone differentially enhance expression of regeneration-associated genes. Exp Neurol 2010;223:183-191.

83. Singh B, Xu QG, Franz CK, et al. Accelerated axon outgrowth, guidance, and target reinnervation across nerve transection gaps following a brief electrical stimulation paradigm. J Neurosurg 2012;116:498-512.

84. Tagami Y, Kurimoto T, Miyoshi T, Morimoto T, Sawai H, Mimura O. Axonal regeneration induced by repetitive electrical stimulation of crushed optic nerve in adult rats. Jpn J Ophthalmol 2009:53:257-266.

85. Thompson NJ, Sengelaub DR, English AW. Enhancement of peripheral nerve regeneration due to treadmill training and electrical stimulation is dependent on androgen receptor signaling. Dev Neurobiol 2014;74:531-540.

86. Udina E, Furey M, Busch S, Silver J, Gordon T, Fouad K. Electrical stimulation of intact peripheral sensory axons in rats promotes outgrowth of their central projections. Exp Neurol 2008;210:238-247.

87. Wan L, Zhang S, Xia R, Ding W. Short-term low-frequency electrical stimulation enhanced remyelination of injured peripheral nerves by inducing the promyelination effect of brain-derived neurotrophic factor on Schwann cell polarization. J Neurosci Res 2010;88:2578-2587.

88. Wang WJ, Zhu H, Li F, Wan LD, Li HC, Ding WL. Electrical stimulation promotes motor nerve regeneration selectivity regardless of end-organ connection. J Neurotrauma 2009;26:641649.

89. Xu C, Kou Y, Zhang P, et al. Electrical stimulation promotes regeneration of defective peripheral nerves after delayed repair intervals lasting under one month. PLoS ONE 2014;9:e105045.

90. Yao CH, Chang RL, Chang SL, Tsai CC, Tsai FJ, Chen YS. Electrical stimulation improves peripheral nerve regeneration in streptozotocin-induced diabetic rats. J Trauma Acute Care Surg 2012;72:199-205.

91. Yeh CC, Lin YC, Tsai FJ, Huang CY, Yao CH, Chen YS. Timing of applying electrical stimulation is an important factor deciding the success rate and maturity of regenerating rat sciatic nerves. Neurorehabil Neural Repair 2010;24:730-735.

92. Huang J, Zhang Y, Lu L, Hu X, Luo Z. Electrical stimulation accelerates nerve regeneration and functional recovery in delayed peripheral nerve injury in rats. Eur J Neurosci 2013;38:36913701 . 
93. Calvey C, Zhou W, Stakleff KS, et al. Short-term electrical stimulation to promote nerve repair and functional recovery in a rat model. J Hand Surg Am 2015;40:314-322.

94. Gordon T, Amirjani N, Edwards DC, Chan KM. Brief postsurgical electrical stimulation accelerates axon regeneration and muscle reinnervation without affecting the functional measures in carpal tunnel syndrome patients. Exp Neurol 2010;223:192-202.

95. Kilmer SL, Carlsen RC. Chronic infusion of agents that increase cyclic AMP concentration enhances the regeneration of mammalian peripheral nerves in vivo. Exp Neurol 1987;95:357-367.

96. Pichichero M, Beer B, Clody DE. Effects of dibutyryl cyclic AMP on restoration of function of damaged sciatic nerve in rats. Science 1973;182:724-725.

97. McQuarrie IG, Grafstein B, Gershon MD. Axonal regeneration in the rat sciatic nerve: effect of a conditioning lesion and of dbcAMP. Brain Res 1977;132:443-453.

98. Han PJ, Shukla S, Subramanian PS, Hoffman PN. Cyclic AMP elevates tubulin expression without increasing intrinsic axon growth capacity. Exp Neurol 2004;189:293-302.

99. Flora G, Joseph G, Patel S, et al. Combining neurotrophintransduced schwann cells and rolipram to promote functional recovery from subacute spinal cord injury. Cell Transplant 2013;22: 2203-2217.

100. Pearse DD, Pereira FC, Marcillo AE, et al. cAMP and Schwann cells promote axonal growth and functional recovery after spinal cord injury. Nat Med 2004;10:610-616.

101. Udina E, Ladak A, Furey M, Brushart T, Tyreman N, Gordon T. Rolipram-induced elevation of cAMP or chondroitinase ABC breakdown of inhibitory proteoglycans in the extracellular matrix promotes peripheral nerve regeneration. Exp Neurol 2010;223: 143-152.

102. Aglah C, Gordon T, Posse De Chaves EI. cAMP promotes neurite outgrowth and extension through protein kinase A but independently of Erk activation in cultured rat motoneurons. Neuropharmacology 2008;55:8-17.

103. Neumann S, Woolf CJ. Regeneration of dorsal column fibers into and beyond the lesion site following adult spinal cord injury. Neuron 1999;23:83-91.

104. Richardson PM, Issa VM. Peripheral injury enhances central regeneration of primary sensory neurones. Nature 1984;309:791793.

105. Davies SJ, Goucher DR, Doller C, Silver J. Robust regeneration of adult sensory axons in degenerating white matter of the adult rat spinal cord. J Neurosci 1999;19:5810-5822.

106. Qiu J, Cai D, Filbin MT. Glial inhibition of nerve regeneration in the mature mammalian CNS. Glia 2000;29:166-174.

107. Goldberg JL, Barres BA. Nogo in nerve regeneration. Nature 2000;403:369-370.

108. Zhao RR, Fawcett,JW. Combination treatment with chondroitinase $\mathrm{ABC}$ in spinal cord injury-breaking the barrier. Neurosci Bull 2013;4:477-483.

109. Campbell G, Anderson PN, Turmaine M, Lieberman AR. GAP-43 in the axons of mammalian CNS neurons regenerating into peripheral nerve grafts. Exp Brain Res 1991;87:67-74.

110. Woolf CJ. Turbocharging neurons for growth: accelerating regeneration in the adult CNS. Nat Neurosci 2001;4:7-9.
111. Bomze HM, Bulsara KR, Iskandar BJ, Caroni P, Skene JH. Spinal axon regeneration evoked by replacing two growth cone proteins in adult neurons. Nat Neurosci 2001;4:38-43.

112. Wood MD, Moore AM, Hunter DA, et al. Affinity-based release of glial-derived neurotrophic factor from fibrin matrices enhances sciatic nerve regeneration. Acta Biomater 2009;5:959-968.

113. Wood MD, Borschel GH, Sakiyama-Elbert SE. Controlled release of glial-derived neurotrophic factor from fibrin matrices containing an affinity-based delivery system. J Biomed Mater Res A 2009;89:909-918.

114. Moore AM, Wood MD, Chenard K, et al. Controlled delivery of glial cell line-derived neurotrophic factor enhances motor nerve regeneration. J Hand Surg Am 2010;35:2008-2017.

115. Wood MD, Macewan MR, French AR, et al. Fibrin matrices with affinity-based delivery systems and neurotrophic factors promote functional nerve regeneration. Biotechnol Bioeng 2010;106:970979.

116. Wood MD, Kim H, Bilbily A, et al. GDNF released from microspheres enhances nerve regeneration after delayed repair. Muscle Nerve 2012;46:122-124.

117. Wood MD, Gordon T, Kim H, et al. Fibrin gels containing GDNF microspheres increase axonal regeneration after delayed peripheral nerve repair. Regen Med 2013;8:27-37.

118. Wood MD, Gordon T, Kemp SW, et al. Functional motor recovery is improved due to local placement of GDNF microspheres after delayed nerve repair. Biotechnol Bioeng 2013;110:1272-1281.

119. Eggers R, De WF, Hoyng SA, et al. Lentiviral vector-mediated gradients of GDNF in the injured peripheral nerve: Effects on nerve coil formation, Schwann cell maturation and myelination. PLoS ONE 2013;8:e71076.

120. Santosa KB, Jesuraj NJ, Viader A, et al. Nerve allografts supplemented with schwann cells overexpressing glial-cell-line-derived neurotrophic factor. Muscle Nerve 2013;47:213-223.

121. Sabatier MJ, Redmon N, Schwartz G, English AW. Treadmill training promotes axon regeneration in injured peripheral nerves. Exp Neurol 2008;211:489-493.

122. Wood K, Wilhelm JC, Sabatier MJ, Liu K, Gu J, English AW. Sex differences in the effectiveness of treadmill training in enhancing axon regeneration in injured peripheral nerves. Dev Neurobiol 2012;72:688-698.

123. Redett R, Jari R, Crawford T, Chen YG, Rohde C, Brushart TM. Peripheral pathways regulate motoneuron collateral dynamics. J Neurosci 2005;25:9406-9412.

124. Sunderland S. Nerve and nerve injuries. Livingstone, Edinburgh, 1978.

125. Wong JN, Olson JL, Morhart MJ, Chan KM. Electrical stimulation enhances sensory recovery: A randomized control trial. Ann Neurol 2015;77:996-1006.

126. Chan KM, Gordon T, Zochodne DW, Power HA. Improving peripheral nerve regeneration: from molecular mechanisms to potential therapeutic targets. Exp Neurol 2014;261:826-835.

127. Placheta E, Wood MD, Lafontaine C, et al. Enhancement of facial nerve motoneuron regeneration through cross-face nerve grafts by adding end-to-side sensory axons. Plast Reconstr Surg 2015;135: 460-471. 